\title{
Damage Characterization of Composite Structures Using Difference Peak Signal-to-Noise Ratio as a Function of Variable Wavelets ( $\triangle \mathrm{PSNR}-\Delta \mathrm{W})$
}

\author{
Mahmoud Zaki Iskandarani \\ Faculty of Science and Information Technology, Department of Basic Sciences, Al-Zaytoonah University of \\ Jordan, Amman, Jordan \\ Email:m.iskandarani@hotmail.com,compcenter@zuj.edu.jo
}

Received 23 March 2016; accepted 24 April 2016; published 28 April 2016

Copyright (C) 2016 by author and Scientific Research Publishing Inc.

This work is licensed under the Creative Commons Attribution International License (CC BY).

http://creativecommons.org/licenses/by/4.0/

(c) (i) Open Access

\begin{abstract}
A novel approach employs the principles of medical image analysis using Wavelet Transform (WT) and Difference Peak Signal-to-Noise Ratio ( $\triangle P S N R$ ). Both techniques are combined as a function of different decomposing levels of wavelets and various image search through and slicing levels, which is implemented under MATLAB environment. In this new approach, the structural change due to damage in the component or the presence of foreign bodies appearing in an image taken for a specific structure is uncovered with its extent determined after applying the search through algorithm. Such alteration of the composite structure, which could be masked by the presence of noise, is accounted for using combined WT and PSNR. Effect of Artifacts and Blurring caused by different wavelet types is investigated before choosing an appropriate wavelet, namely Sym8. This new approach, which also reduces the required layers of search within an image, produces a pattern matrix per damaged area and is an excellent way in tracing and modeling damage in structures with ability to predict effects of further damage on components and further application to artificial limbs that could suffer damage and affect users mobility.
\end{abstract}

\section{Keywords}

Image Processing, Wavelet Transform, PSNR, Structural Damage, Correlation, Medical Images

\section{Introduction}

Wavelet transform (WT) is a useful tool for image processing. It plays a critical role in many non-medical and

How to cite this paper: Iskandarani, M.Z. (2016) Damage Characterization of Composite Structures Using Difference Peak Signal-to-Noise Ratio as a Function of Variable Wavelets ( $\triangle P S N R-\Delta W)$. Engineering, 8, 204-225. 
medical applications. Data contained in an image are generally contaminated by noise or interfering signals, which can mask the actual data of interest. Furthermore noise can be caused by other means such as transmission errors and compression. Thus the noise removal is essential on many occasions before data in an image is analyzed reliably. The need is for an efficient and effective denoising algorithm to be used to recover data of interest without causing too many changes and artifacts to the image under consideration such as blurring.

Noise removal and reconstruction of original image is carried out through wavelet coefficients which are the result of decomposition in wavelet transform by eliminating the small coefficients normally associated with noise. The original image can be obtained by an algorithm using the noise free coefficients. Such reconstructed image is possible using a threshold function, which estimates noise levels.

The Wavelet Transform offers better image resolution employing orthogonal wavelet decomposition process. The overall process splits the approximation coefficients sub-band of the image into four sub-bands, thus obtaining a sub-band of coefficients (Approximate) and three sub-bands of detail coefficients (Horizontal, Vertical, Diagonal) as shown in Figure 1. Further transformations can be carried out by splitting the new approximation coefficient sub-band in a recursive way, where each detail coefficients sub-band is also decomposed into four sub-bands using the same approach as in approximation sub-band splitting. The Wavelet Transform for an image gives a large number of sub-bands of wavelet coefficients with different resolutions. The various decomposition levels can be correlated to such resolutions and tested using Peak Signal-to-Noise Ratio (PSNR) to measure each decomposition level effectiveness and hence can correlate all used levels to more accurately determine areas and levels of critical damage appearing within an image [1]-[6].

In this paper component structural degradation is investigated in RIM composite samples using two powerful image investigation tools, namely WT and PSNR in a novel way. Search through and slicing algorithm of images representing components under inspection is a very important aiding technique in establishing damage level, however, to reduce testing time taken by the number of iterations and inspected layers of an image, Difference Peak Signal-to-Noise-Ration ( $\triangle \mathrm{PSNR}$ ) as a function of Wavelet Transform (WT) is used to narrow the domain of search and to highlight areas of damages more accurately. Such approach can show how degraded a known image becomes, indicating changes in the contents of the image. The new approach applies the combined algorithms under MATLAB environment to search through images of composite structures (images obtained through wavelength variation and RGB recombination).

\section{Experimental Results}

An analytical approach is used to first establish the most appropriate wavelet type maximum level of decomposition by employing 4 main types of wavelets with 5 levels of composition and applying them to a specific image layer for both S1 and S2 RIM composite samples. This is shown in Figures 2-9, where M is layer number and $\mathrm{N}$ is decomposition level. Table 1 shows initial observations regarding tried and tested wavelets. The MATLAB environment provided the simulation process. The examined images belong to RIM composite structures similar to materials used to produce artificial limbs. Such composites suffered different levels of controlled load impacts on the surface at angles $\pi / 2$ and $\pi / 6$.

\section{Analysis and Discussion}

From Figures 2-9 and Table 1, the following is realized:

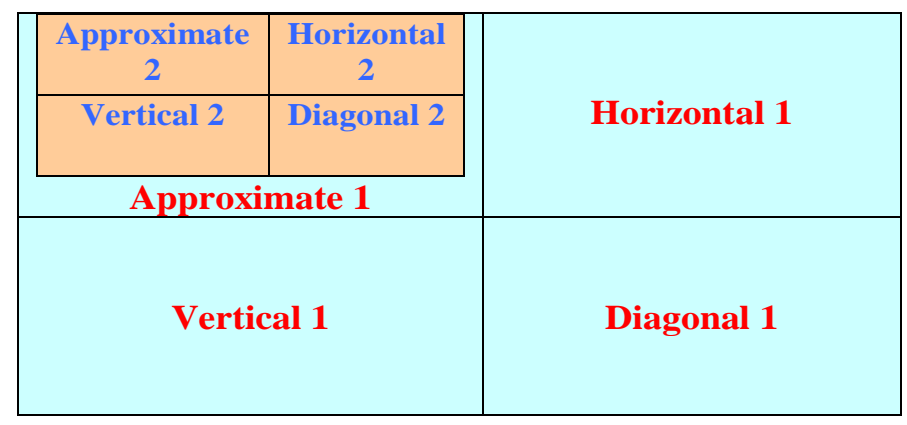

Figure 1. Two levels wavelet transformation. 


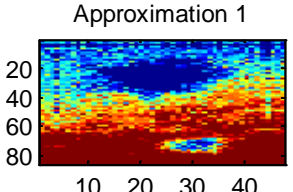

$\begin{array}{llll}10 & 20 & 30 & 40\end{array}$

Approximation 2

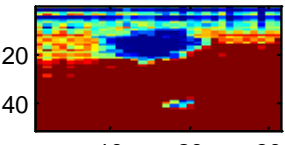

$\begin{array}{lll}10 & 20 & 30\end{array}$

Approximation 3

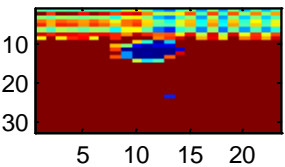

Approximation 4
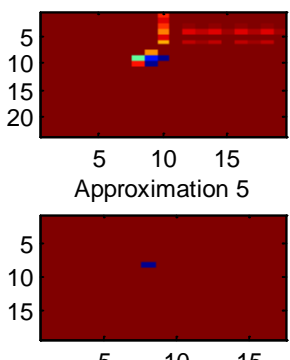

Horizontal 1

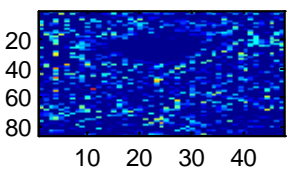

Horizontal 2

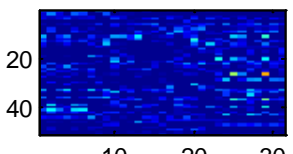

Horizontal 3

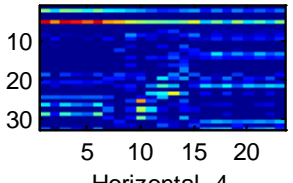

Horizontal 4
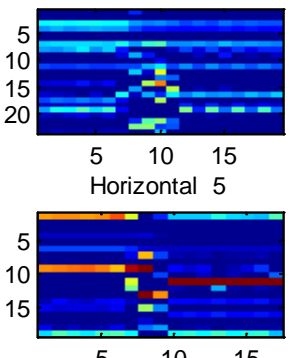

Vertical 1

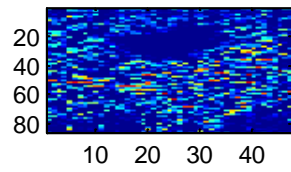

Vertical 2
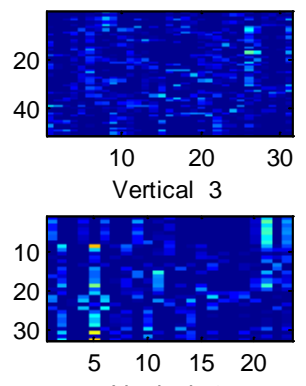

Vertical 4
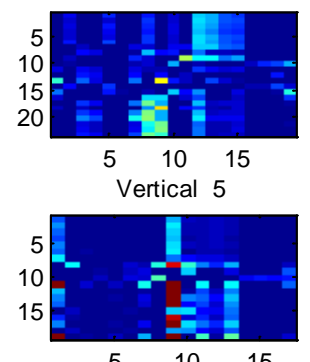

Diagonal 1
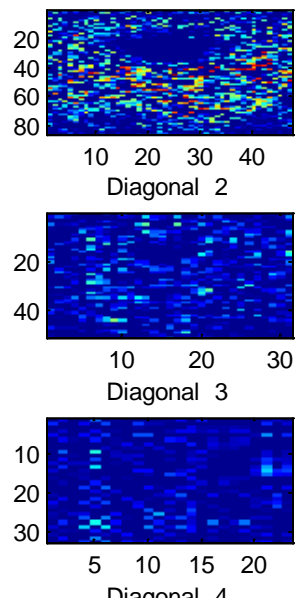

Diagonal 4
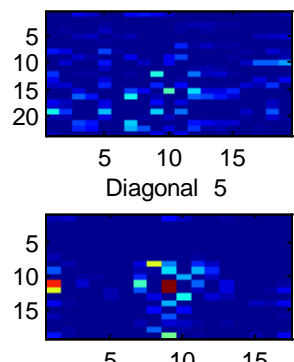

Figure 2. S1-N5-M13-Sym8.
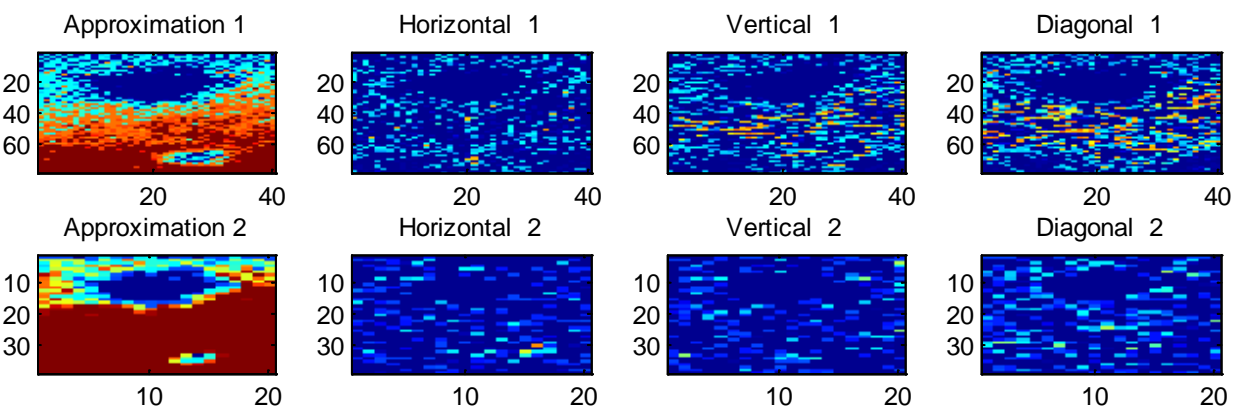

Horizontal

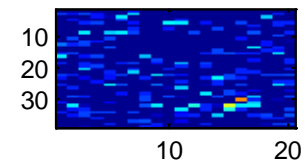

Vertical 2

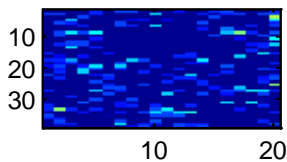

Diagonal 2

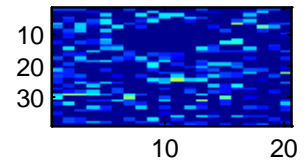

Horizontal 3

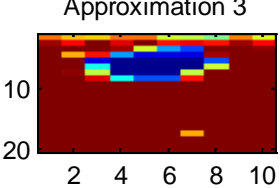

Approximation 4

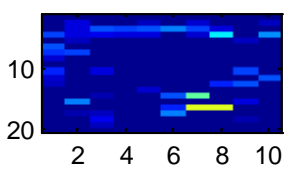

Vertical 3

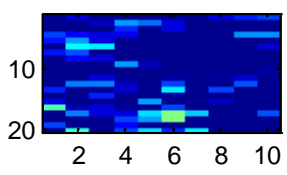

Diagonal 3

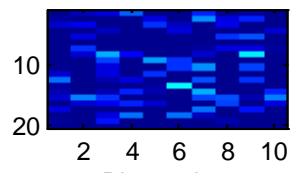

Diagonal 4
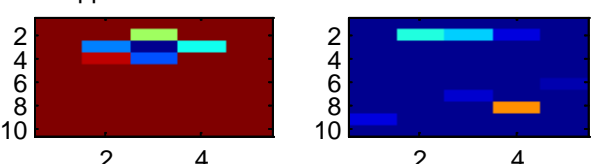

Approximation 5

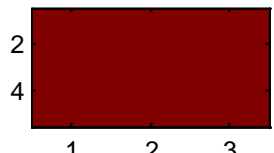

Horizontal 5
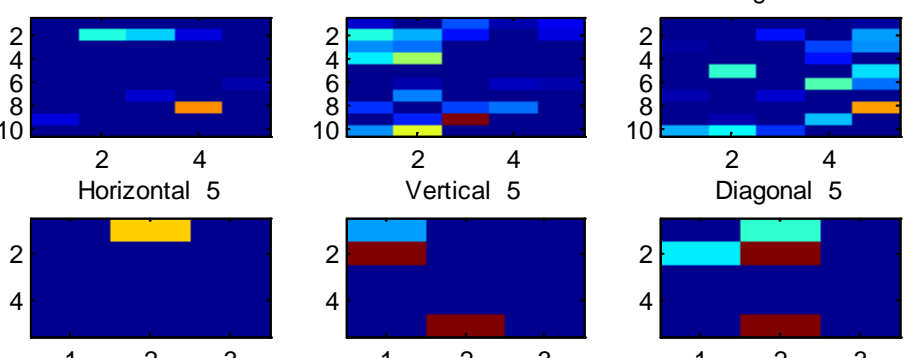

Diagonal 5
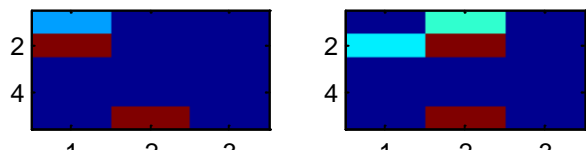

Figure 3. S1-N5-M13-Haar. 


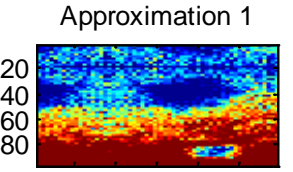

1020304050

Approximation 2

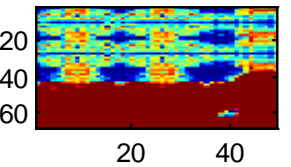

Approximation 3

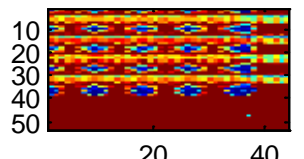

Approximation 4

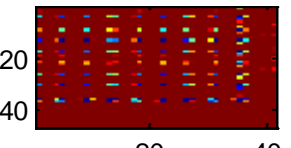

20

Approximation 5

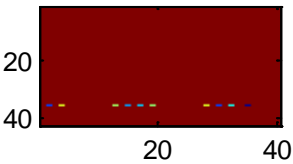

Horizontal 1

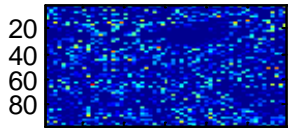

1020304050

Horizontal 2

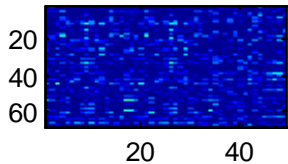

Horizontal 3

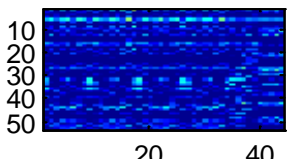

$20 \quad 40$

Horizontal 4

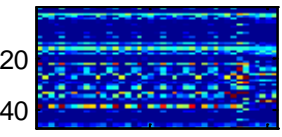

20

Horizontal 5

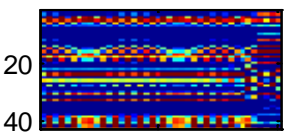

$20 \quad 40$
Vertical 1

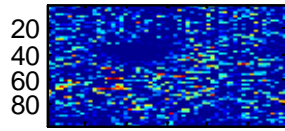

1020304050

Vertical 2

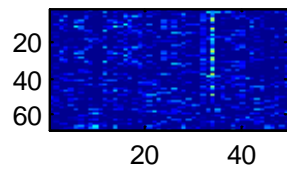

Vertical 3

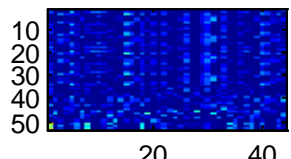

Vertical 4

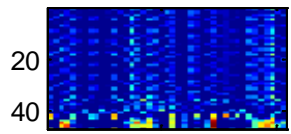

2040

Vertical 5

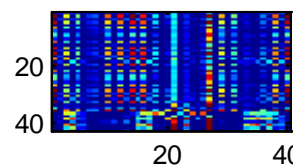

Diagonal 1

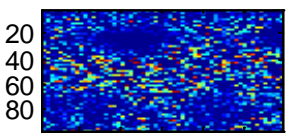

1020304050

Diagonal 2

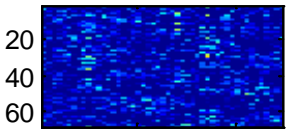

$20 \quad 40$

Diagonal 3

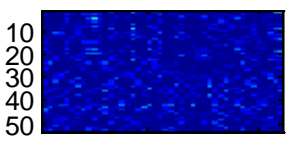

$20 \quad 40$

Diagonal 4

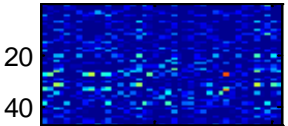

$20 \quad 40$

Diagonal 5

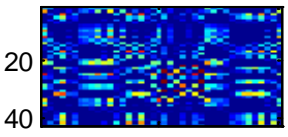

20

Figure 4. S1-N5-M13-Db20.

Approximation 1

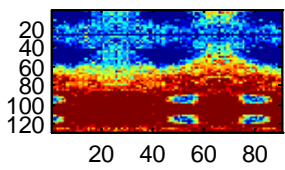

Approximation 2

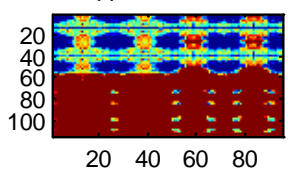

Approximation 3
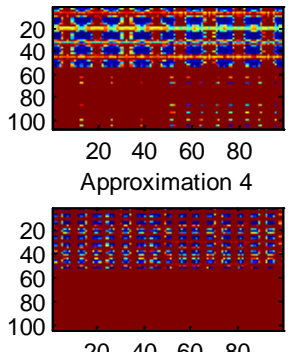

$\begin{array}{llll}20 & 40 & 60 & 80\end{array}$

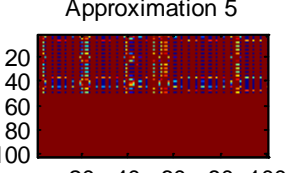

$\begin{array}{lllll}20 & 40 & 60 & 80 & 100\end{array}$
Horizontal 1

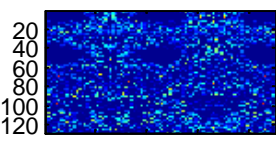

$\begin{array}{llll}20 & 40 & 60 & 80\end{array}$

Horizontal 2

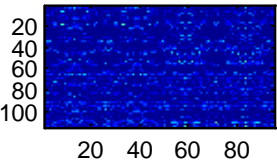

Horizontal 3
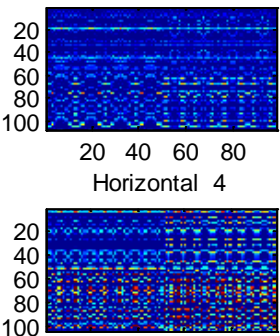

$\begin{array}{llll}20 & 40 \quad 60 \quad 80\end{array}$

Horizontal 5

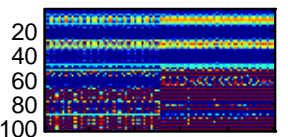

$\begin{array}{lllll}20 & 40 & 60 & 80 & 100\end{array}$
Vertical 1

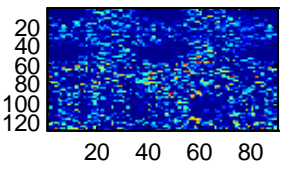

Vertical 2

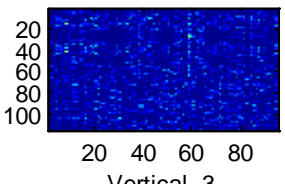

Vertical 3

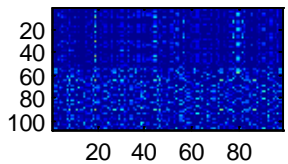

Vertical 4

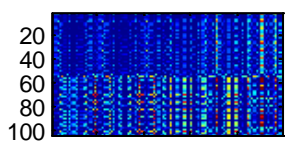

$20 \quad 40 \quad 60 \quad 80$

Vertical 5

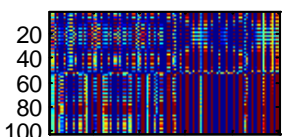

$\begin{array}{lllll}20 & 40 & 60 & 80 & 100\end{array}$
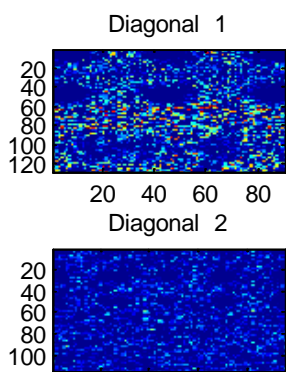

$\begin{array}{llll}20 & 40 \quad 60 \quad 80\end{array}$

Diagonal 3

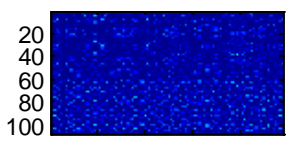

$\begin{array}{llll}20 & 40 & 60 & 80\end{array}$

Diagonal 4

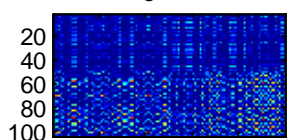

$\begin{array}{llll}20 & 40 \quad 60 \quad 80\end{array}$

Diagonal 5

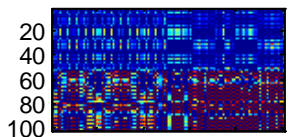

$\begin{array}{lllll}20 & 40 & 60 & 80 & 100\end{array}$

Figure 5. S1-N5-M13-Dmey. 

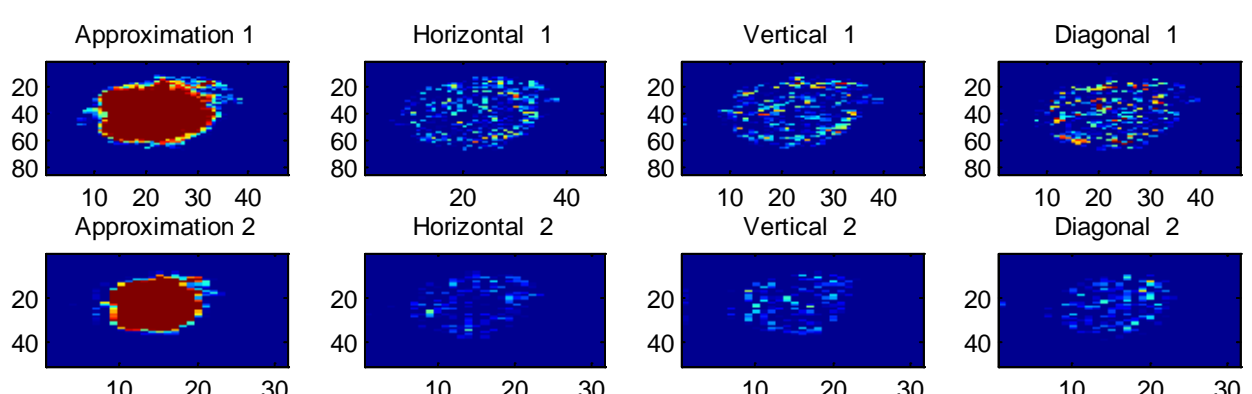

Horizontal 2
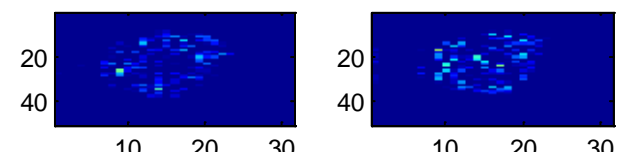

Diagonal 2

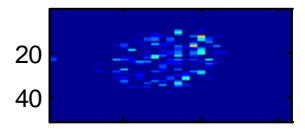

Horizontal 3
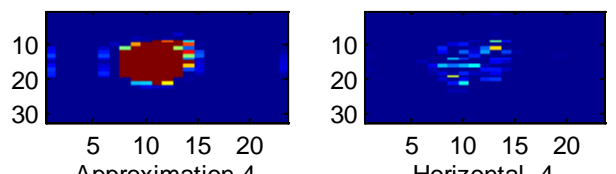

Vertical 3

$\begin{array}{lll}10 & 20 & 30\end{array}$

Diagonal 3
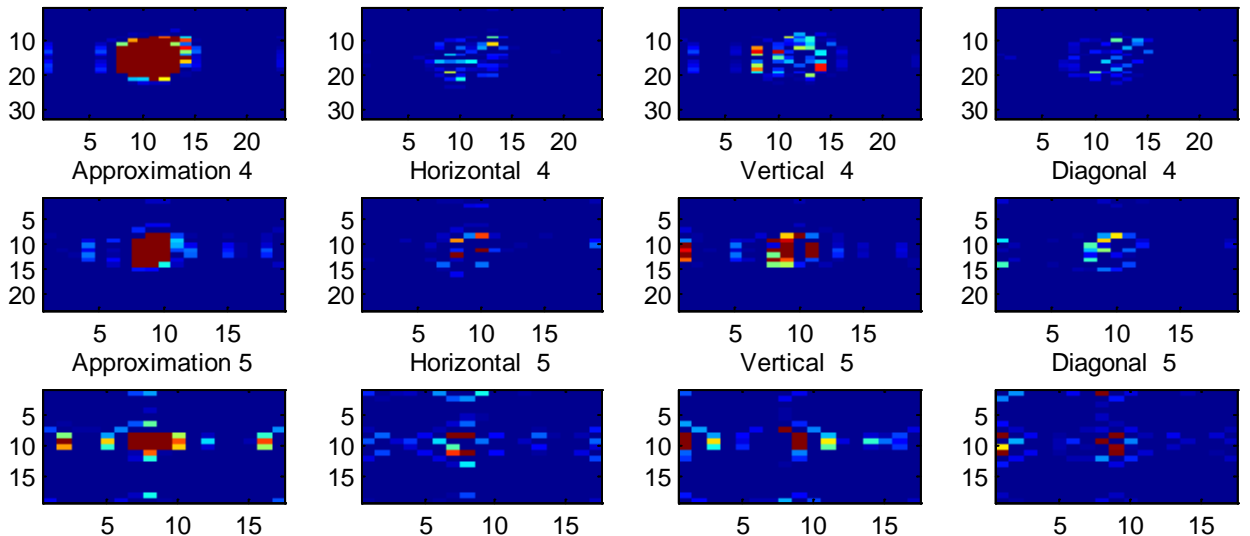

Figure 6. S2-N5-M10-Sym8.

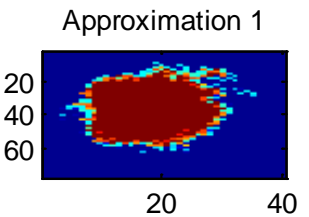

Approximation 2

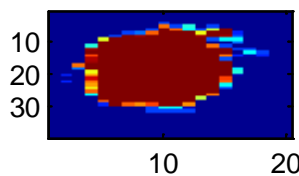

Approximation 3

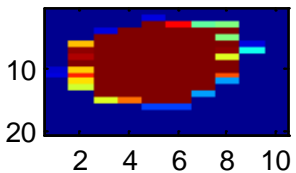

Approximation 4

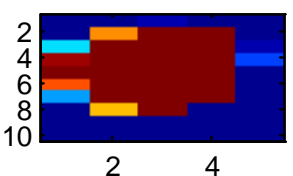

Approximation 5

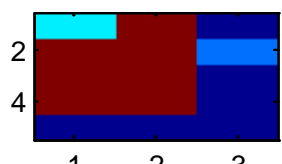

Horizontal 1

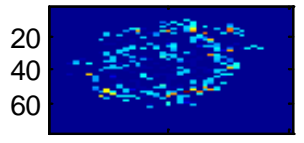

20

Horizontal 2

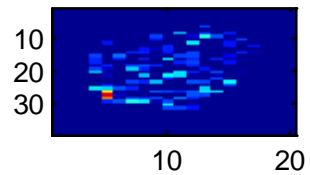

Horizontal 3

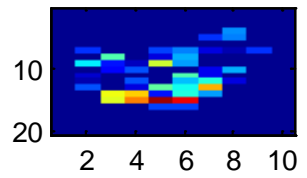

Horizontal 4

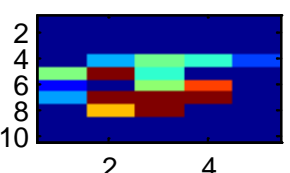

Horizontal 5

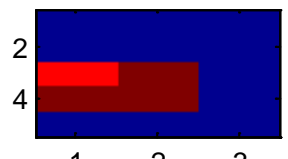

Vertical 1

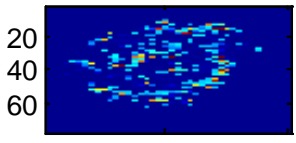

20

Vertical 2

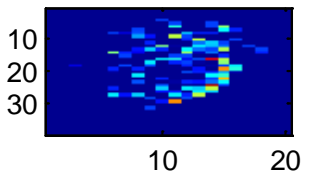

Vertical 3

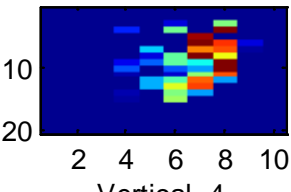

Vertical 4

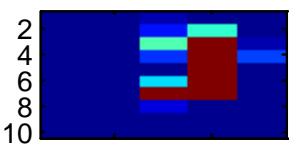

24

Vertical 5

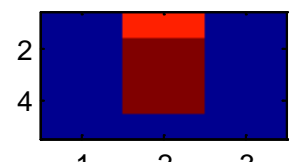

Diagonal 1

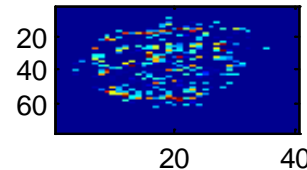

Diagonal 2

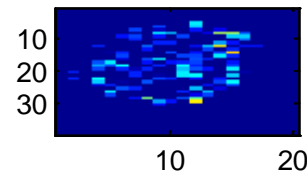

Diagonal 3

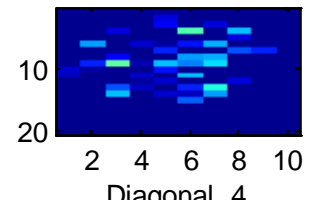

Diagonal 4

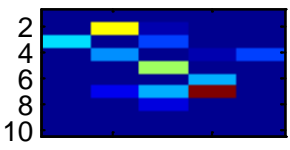

24

Diagonal 5

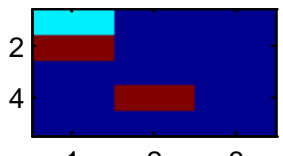

Figure 7. S2-N5-M10-Haar. 

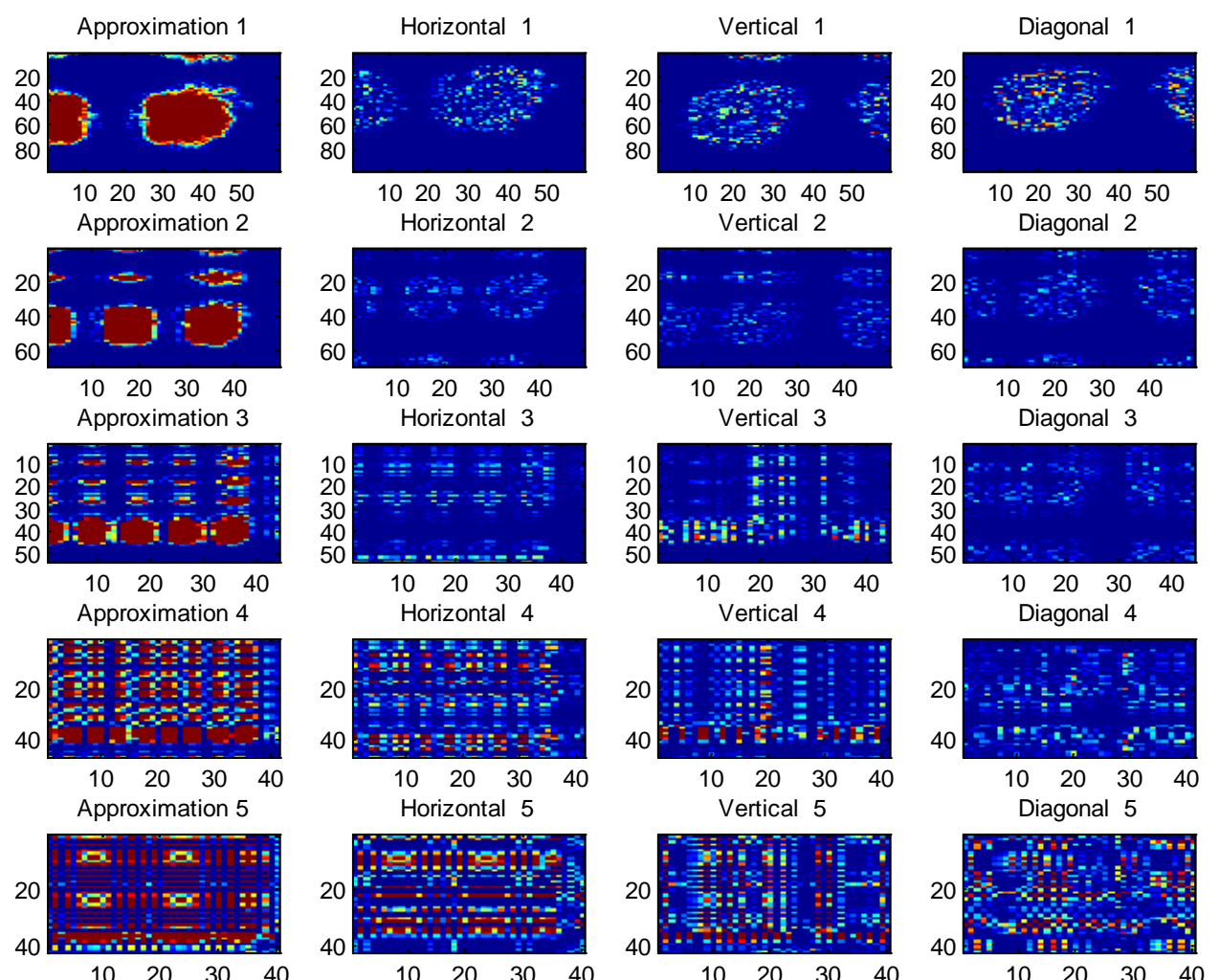

$\begin{array}{llll}10 & 20 & 30 & 40\end{array}$

Diagonal 3
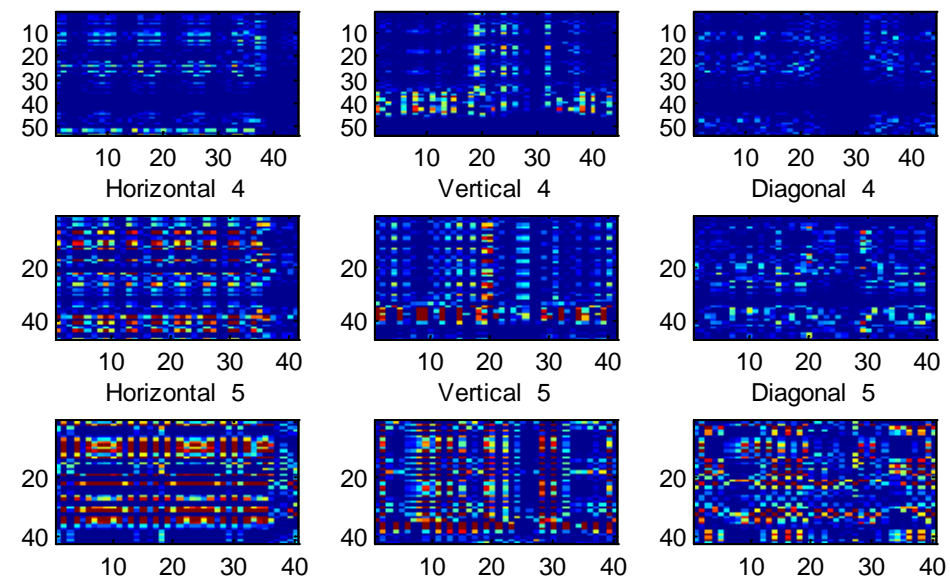

Figure 8. S2-N5-M10-Db20.

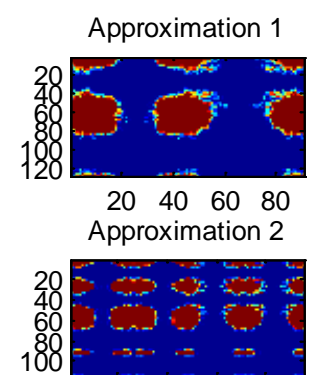

$20 \quad 40 \quad 60 \quad 80$

Approximation 3

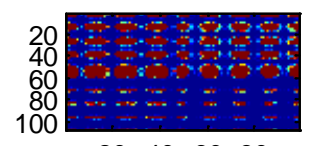

$2040 \quad 60 \quad 80$

Approximation 4

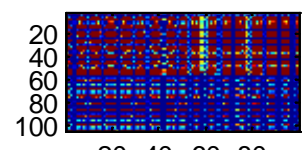

$204060 \quad 80$

Approximation 5

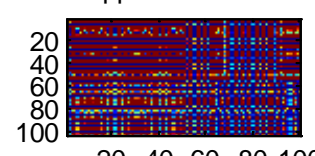

$20 \quad 4060 \quad 80100$

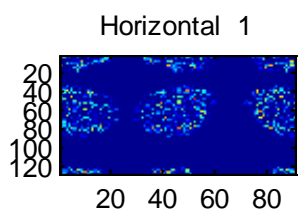

Horizontal 2

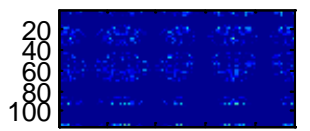

$20 \quad 40 \quad 60 \quad 80$

Horizontal 3

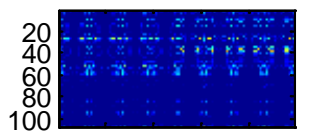

$20 \quad 40 \quad 60 \quad 80$

Horizontal 4

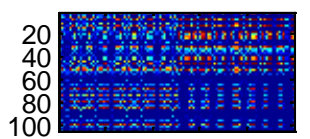

$20 \quad 40 \quad 60 \quad 80$

Horizontal 5

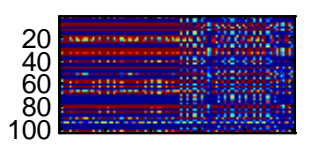

$2040 \quad 60 \quad 80 \quad 100$
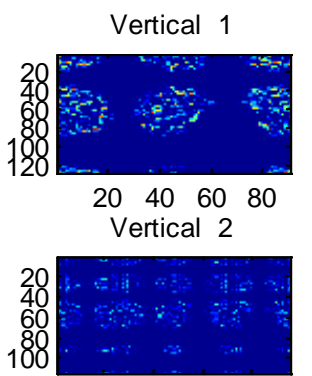

$20 \quad 40 \quad 60 \quad 80$

Vertical 3

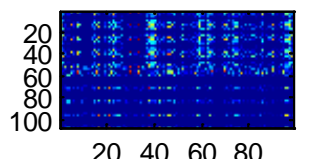

406080

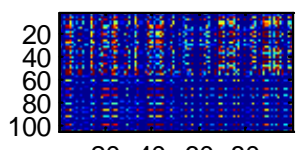

$20 \quad 40 \quad 60 \quad 80$

Vertical 5

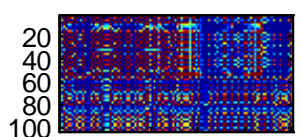

$20 \quad 40 \quad 60 \quad 80100$
Diagonal 1
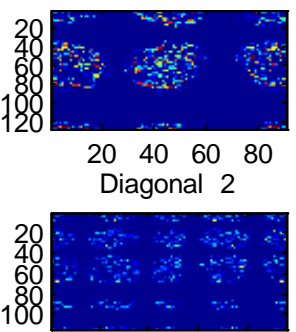

$\begin{array}{llll}20 & 40 \quad 60 \quad 80\end{array}$

Diagonal 3

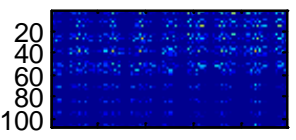

$20 \quad 40 \quad 60 \quad 80$

Diagonal 4

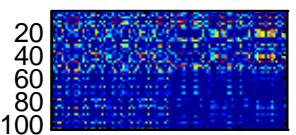

$20 \quad 40 \quad 60 \quad 80$

Diagonal 5

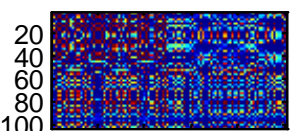

$20 \quad 40 \quad 60 \quad 80 \quad 100$

Figure 9. S2-N5-M10-Dmey. 
Table 1. Wavelet experimentation.

\begin{tabular}{cc}
\hline Type & Observations \\
\hline Haar & Blurring \\
Sym8 & Clear Images \\
Db20 & Artifacts \\
Dmey & Artifacts \\
\hline
\end{tabular}

1) Wavelets such as DB20 and Dmey cause artifacts and mirror effect to the damage under evaluation and will result in data that will present the damage as amplified compared to its real and actual situation.

2) Higher levels of decomposition are desirable as it reveals more details of the damage level and spread.

3) wavelets that cause blurring such as Haar needs further analysis in correlation to damage type and decomposition level [7]-[12]

Figures 10-27 show searched through image for RIM composite that suffered impact damage in two places, one at angle $\pi / 2$ and the other at angle $\pi / 6$ While Figures $28-40$ show searched through image for RIM composite that suffered fiber breakage and fiber extraction.

The new and novel approach is carried out as follows:

1) Each layer of the cycled image shown in Figures 10-40 is cycled through five times corresponding to the five levels of decomposition $(\mathrm{N})$ and then PSNR is each time.

2) The process is carried twice for both Sym8 and Haar in order to establish both blurring effect and effect of number of decomposition levels on the accuracy of pinpointing damage area and level.

3) Difference PSNR ( $\triangle \mathrm{PSNR}$ ) is carried out with first decomposition level used as a reference. This is analogue to PSNR using a reference image when computed.

Figures 41-44 show both samples S1 and S2 tested using this approach.

From Figures 41-44, the following is evident:

1) S2 has suffered a more severe damage and fiber breakage, which is evident at decomposition levels 4 and 5 of Sym8 wavelet, where the characteristics show an inversion in the curve direction relating searched layers to $\triangle$ PSNR as a function of wavelet type and level, where S1 which is known to have suffered less damage show a continuous curve with no breaks or inversion at $\mathrm{N}=4, \mathrm{~N}=5$.

2) For both $S 1$ and $S 2$ that suffered different levels of damage, Haar characteristics did not reveal a difference between them as shown in Figures 42-44. This is due to blurring effect at higher decomposition levels and was shown for S1 and S2 in Figures 3-7.

From Figures 41-44 and using the following expressions, it is now possible to accurately determine the layers of interest within an image and to establish a reference equation to compute damage level.

1) For S1 (Light Impact Damage—LID), the expressions are:

$$
Q_{T}=\left(\frac{M+2}{2}\right)
$$

Transition layer from undamaged to damaged area within the sample.

$$
Q_{M}=\left[\left(\frac{M+2}{2}\right)+1\right]
$$

Exact layer at which the damaged area first noticed.

2) For S2 (Heavy Impact Damage-HID and fiber breakage), the expressions are:

$$
Q_{T}=\left[\left(\frac{M+1}{2}\right)-1\right]
$$

Transition layer from undamaged to damaged area within the sample.

$$
Q_{M}=\left(\frac{M+1}{2}\right)
$$

Exact layer at which the damaged area first noticed. 


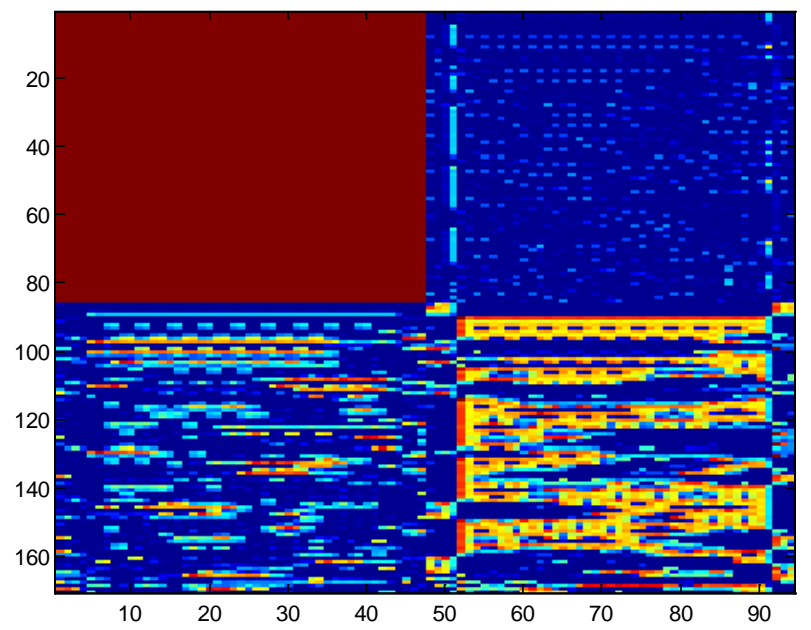

Figure 10. S1-N1-M1 $(80 \times 156)$.

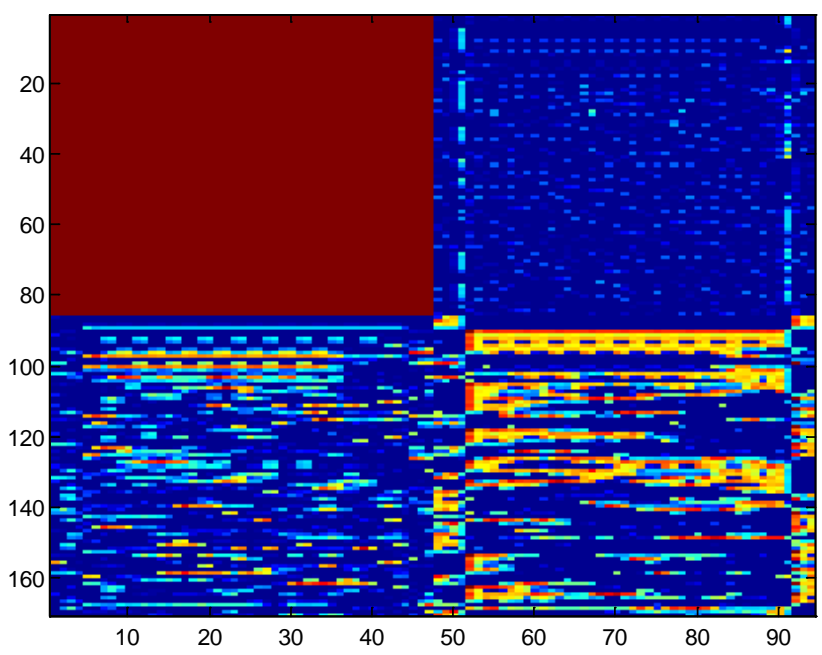

Figure 11. S1-N1-M2 $(80 \times 156)$.

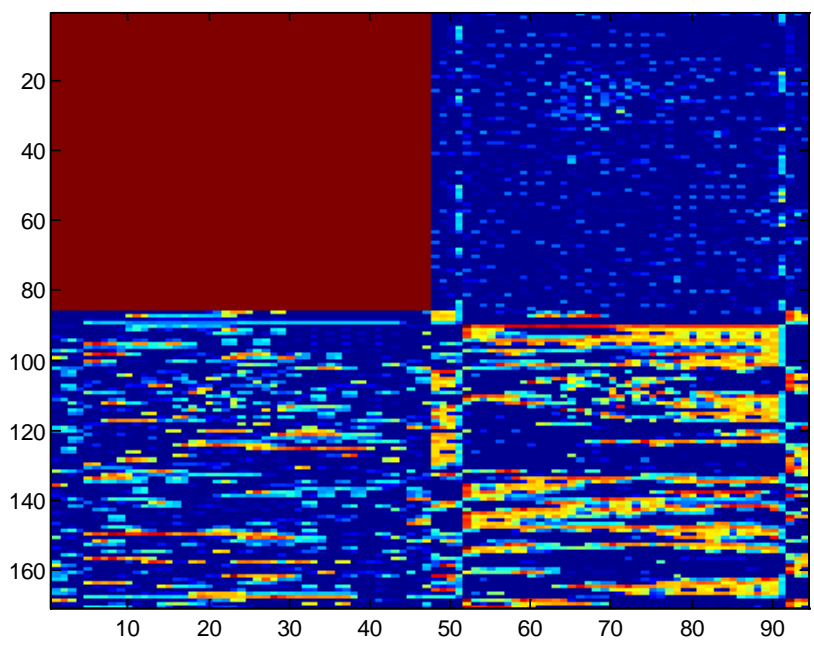

Figure 12. S1-N1-M3 (80 × 156). 


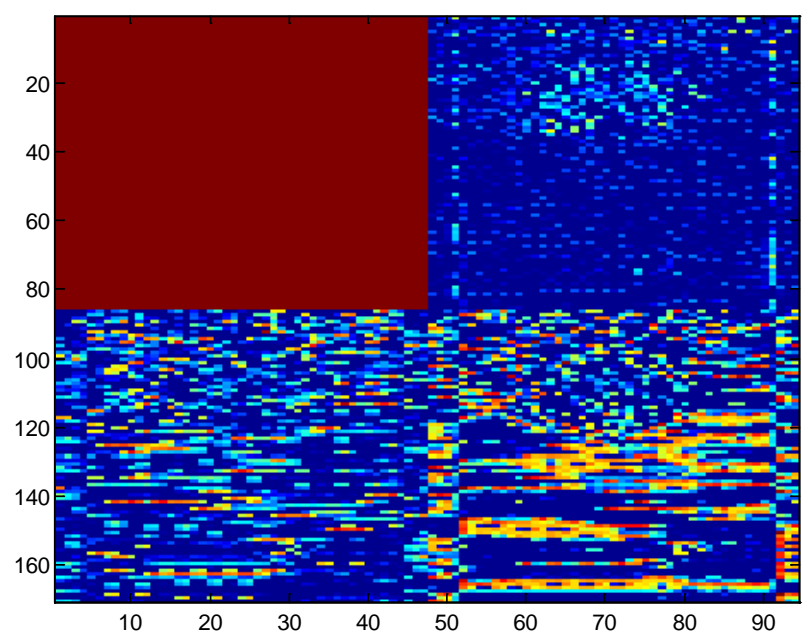

Figure 13. S1-N1-M4 (80 × 156).

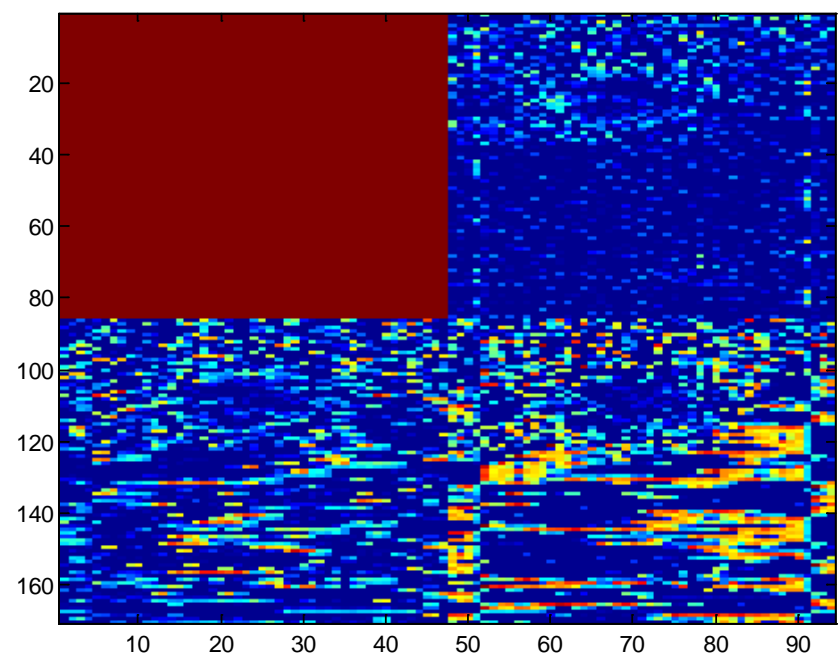

Figure 14. S1-N1-M5 (80 × 156).

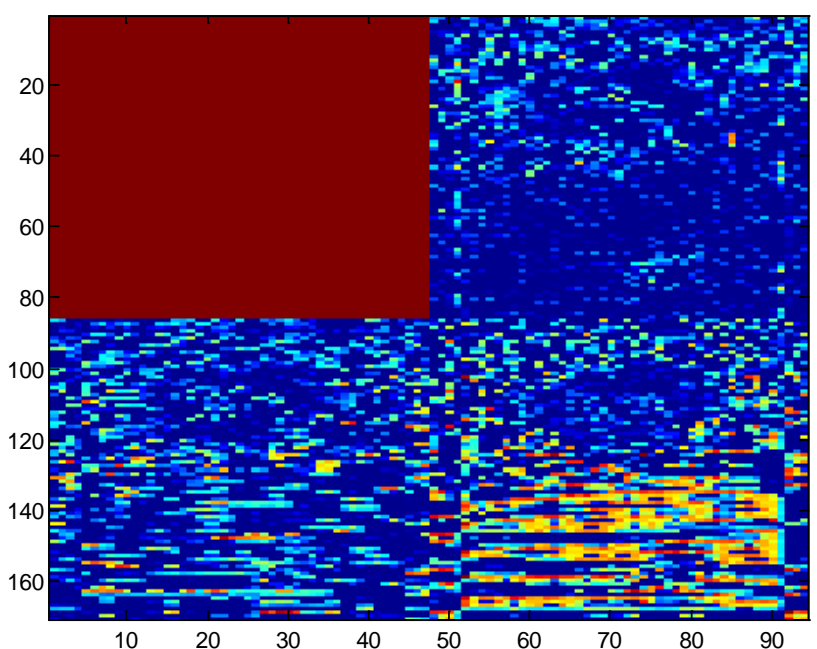

Figure 15. S1-N1-M6 $(80 \times 156)$. 


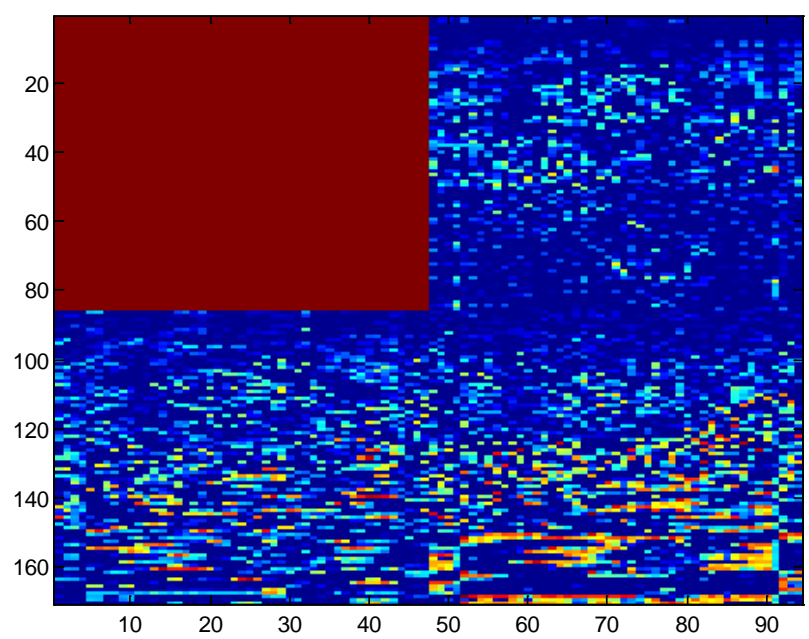

Figure 16. S1-N1-M7 (80 × 156).

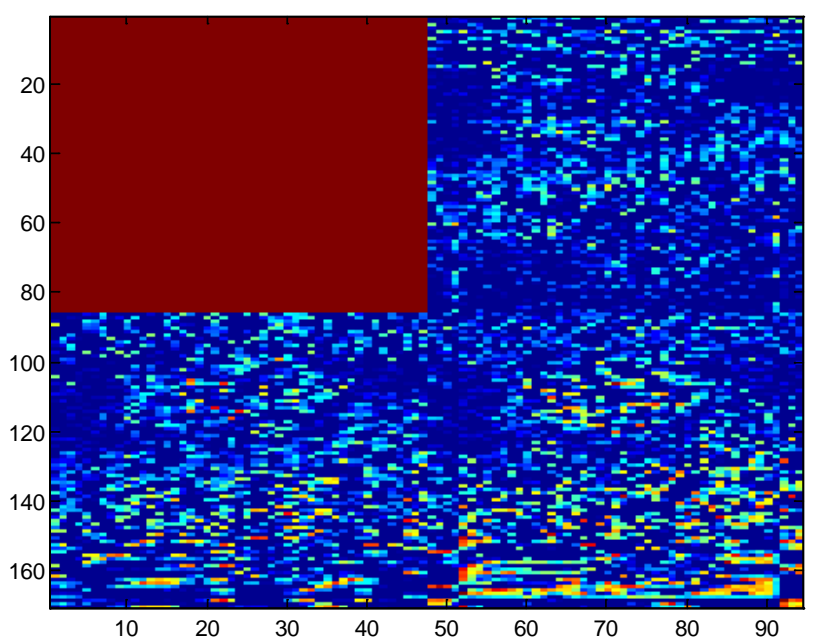

Figure 17. S1-N1-M8 $(80 \times 156)$.

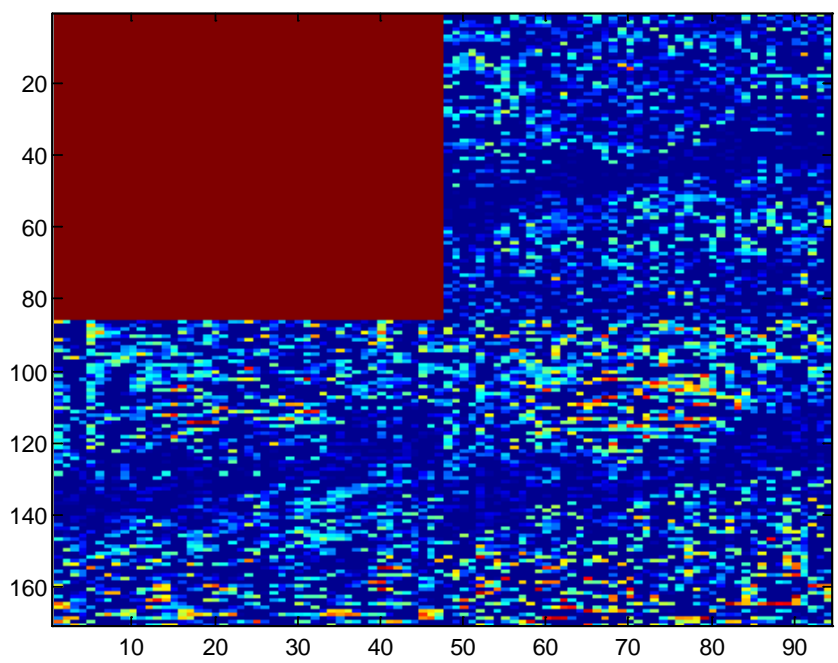

Figure 18. S1-N1-M9 $(80 \times 156)$. 


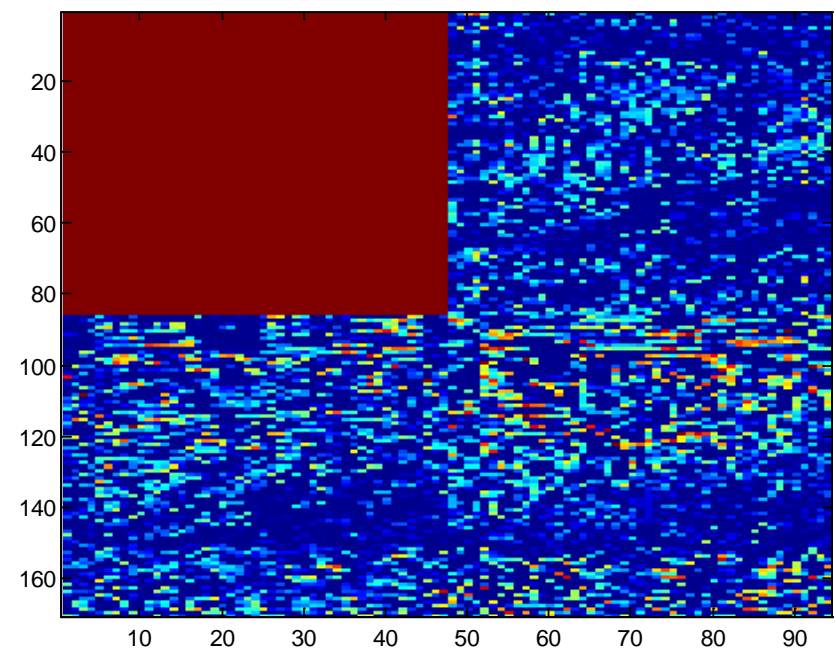

Figure 19. S1-N1-M10 $(80 \times 156)$.

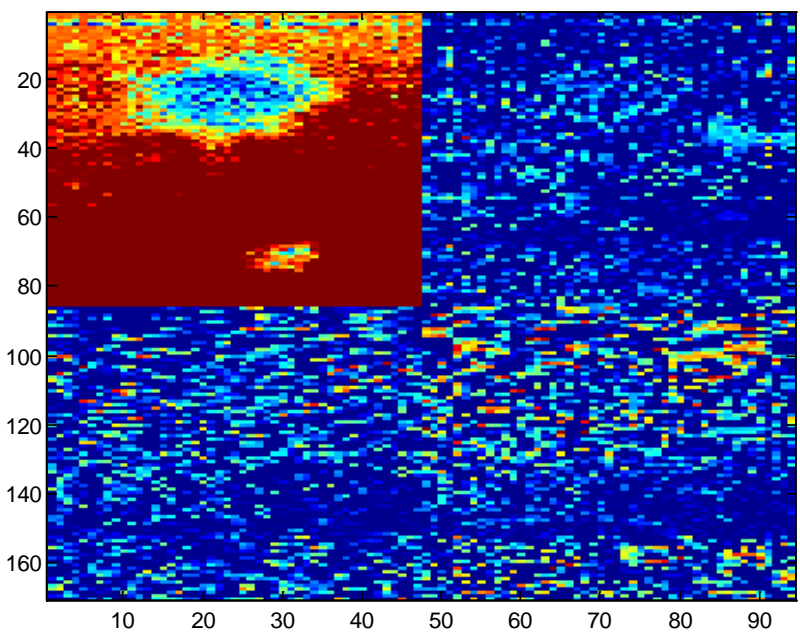

Figure 20. S1-N1-M11 $(80 \times 156)$.

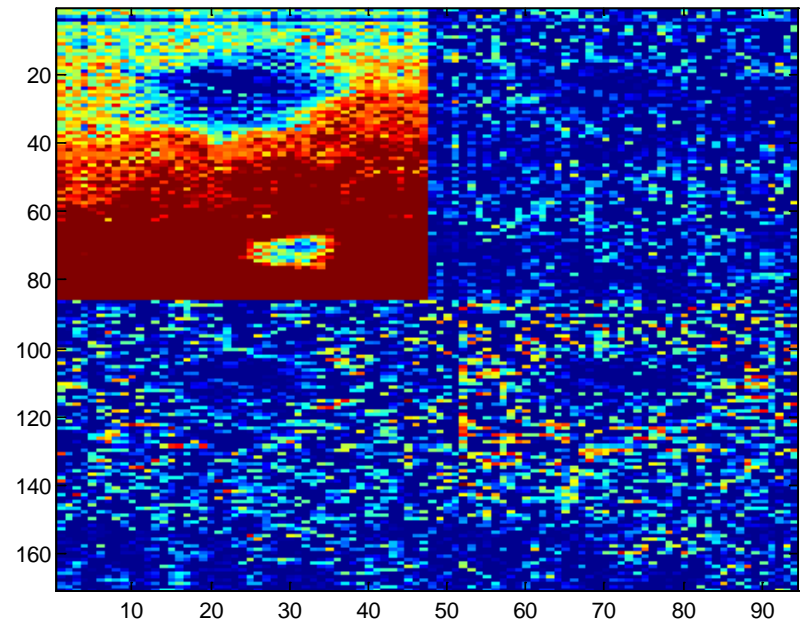

Figure 21. S1-N1-M12 (80 × 156). 


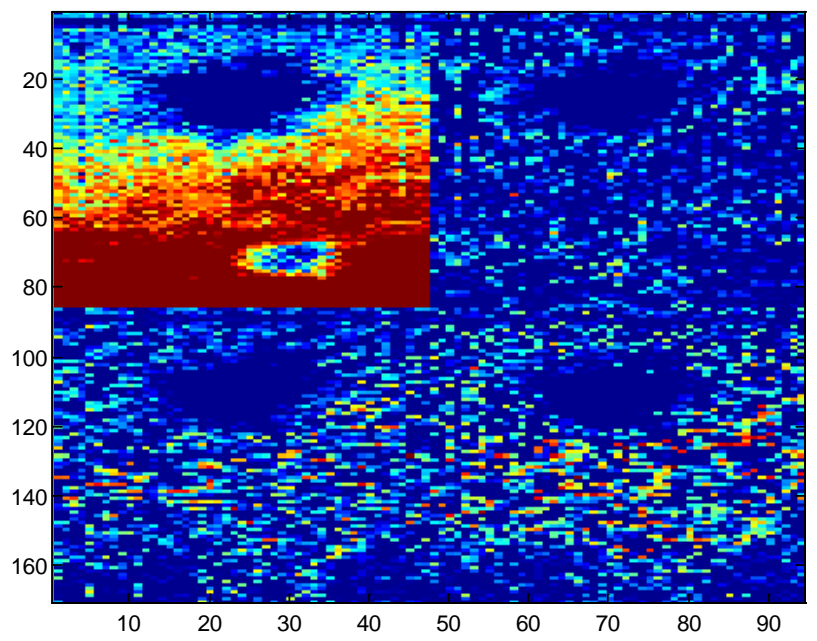

Figure 22. S1-N1-M13 $(80 \times 156)$.

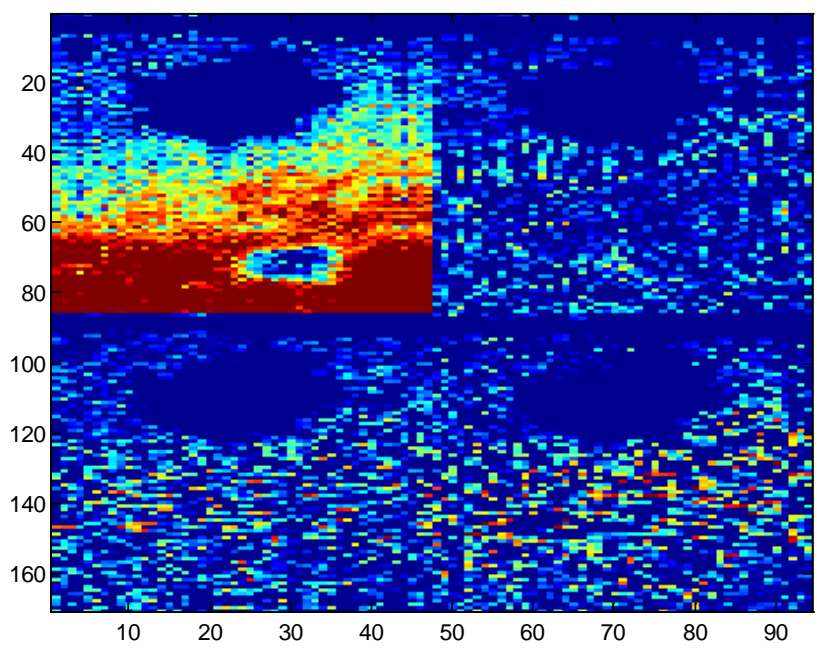

Figure 23. S1-N1-M14 $(80 \times 156)$.

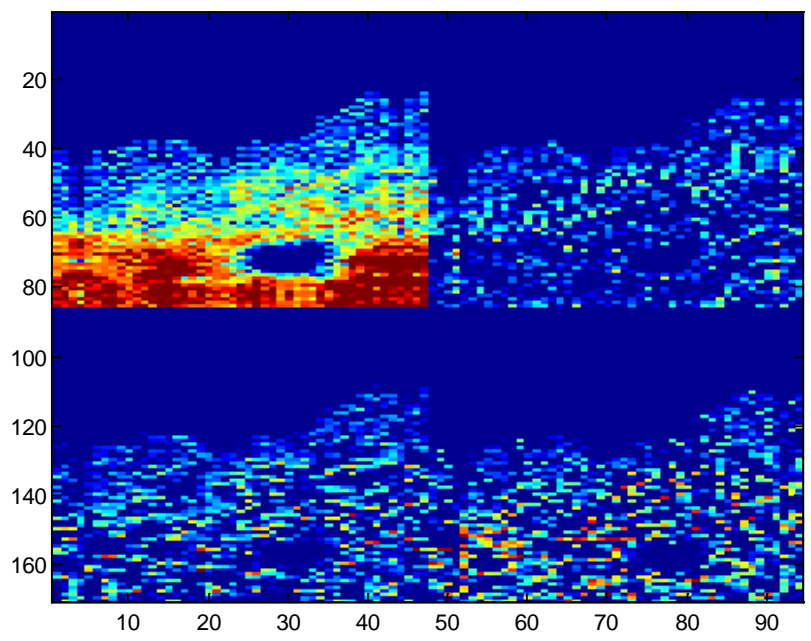

Figure 24. S1-N1-M15 (80 × 156). 


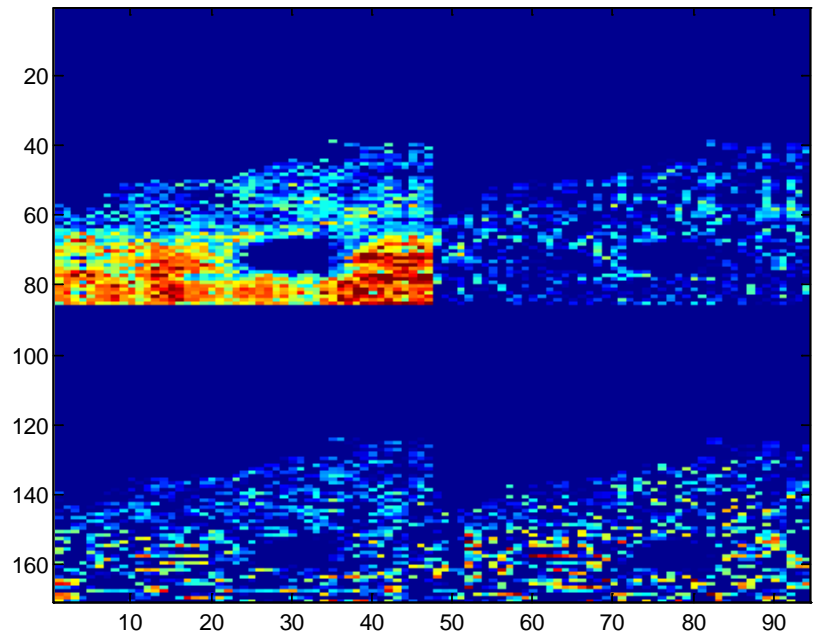

Figure 25. S1-N1-M16 $(80 \times 156)$.

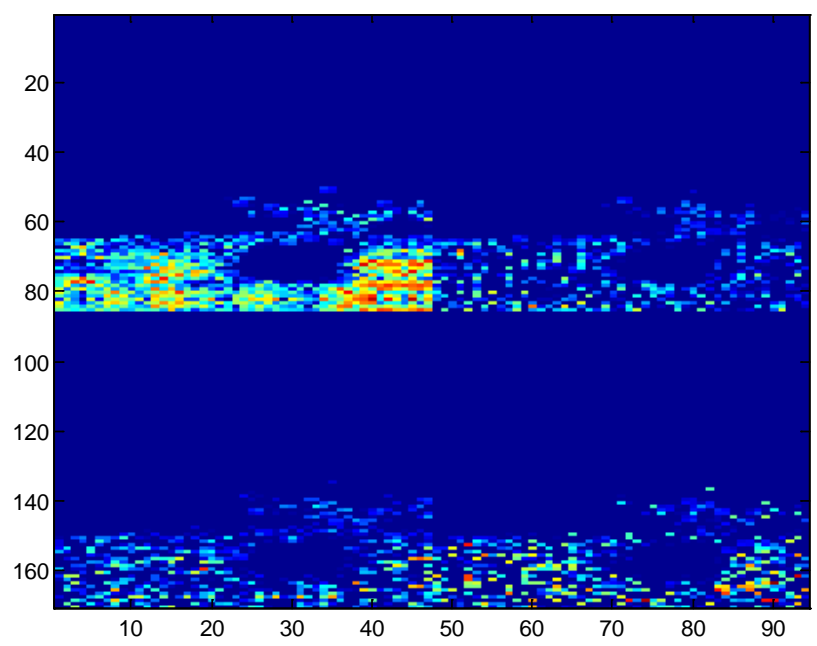

Figure 26. S1-N1-M17 (80 × 156).

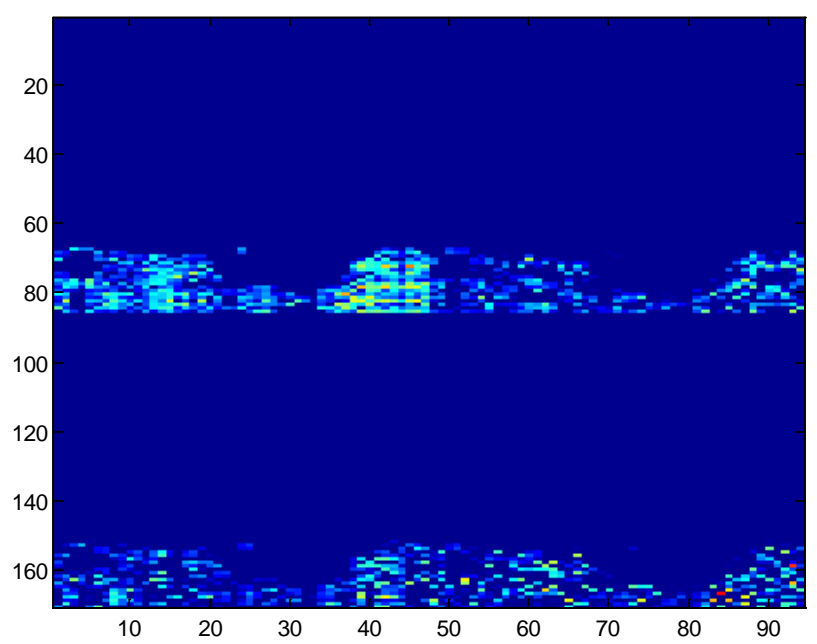

Figure 27. S1-N1-M18 $(80 \times 156)$. 


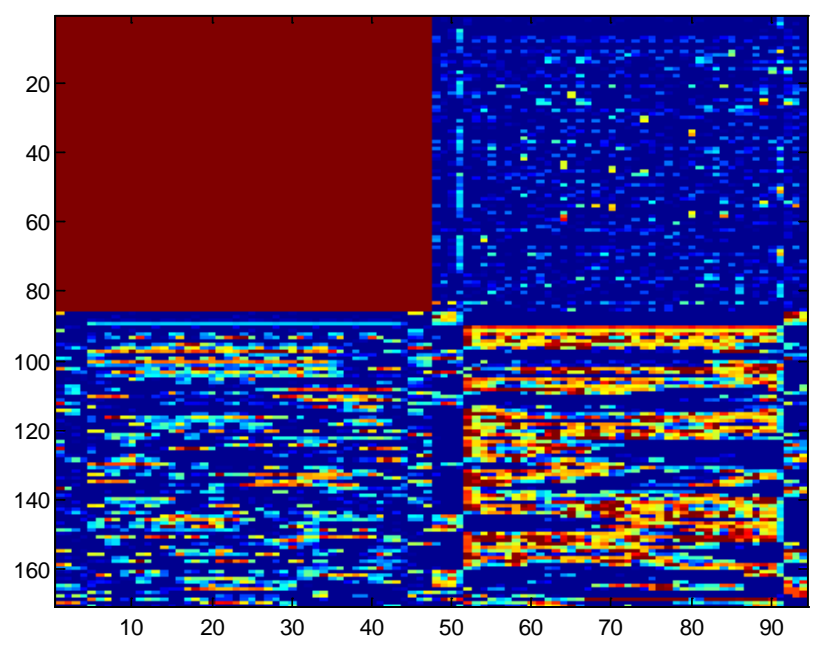

Figure 28. S2-N1-M1 (80 × 156).

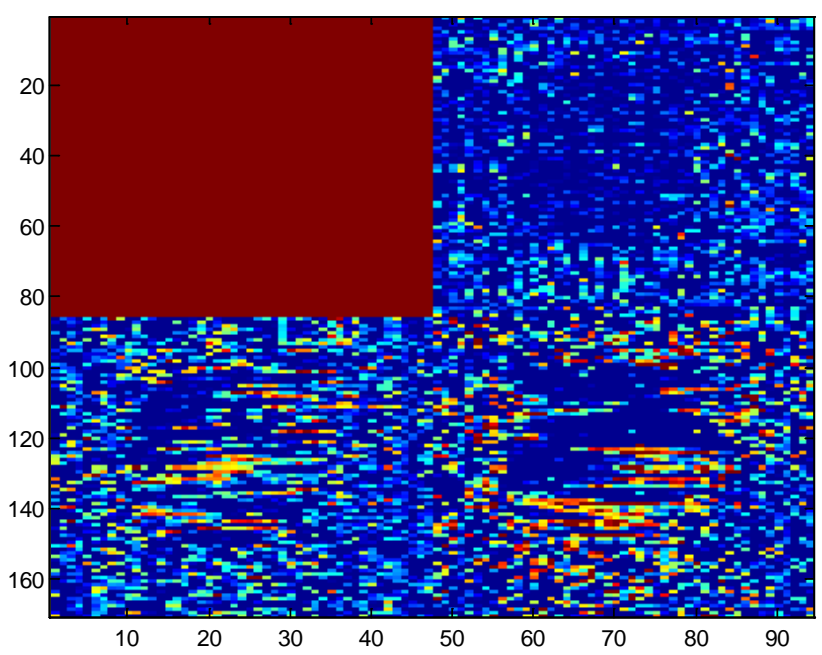

Figure 29. S2-N1-M2 (80 × 156).

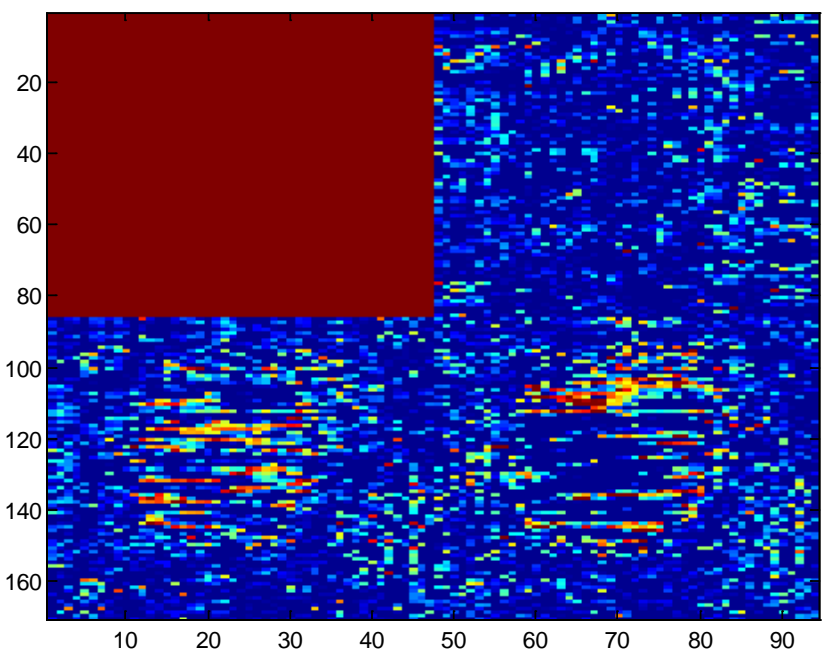

Figure 30. S2-N1-M3 (80 × 156). 


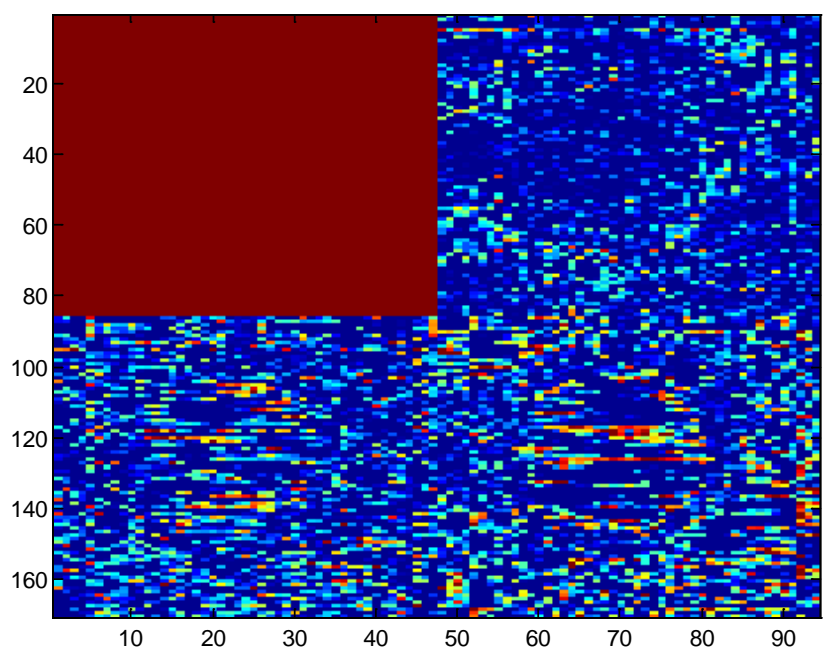

Figure 31. S2-N1-M4 (80 × 156).

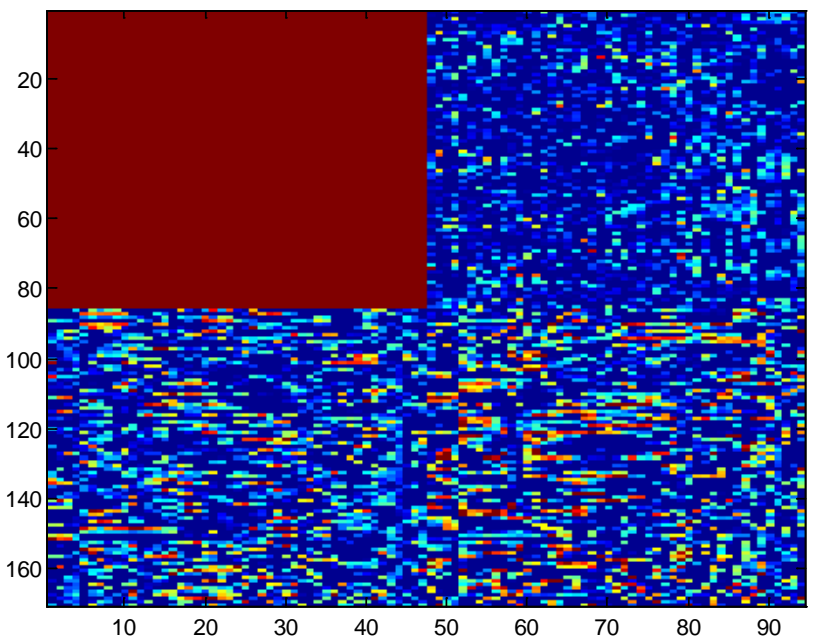

Figure 32. S2-N1-M5 (80 × 156).

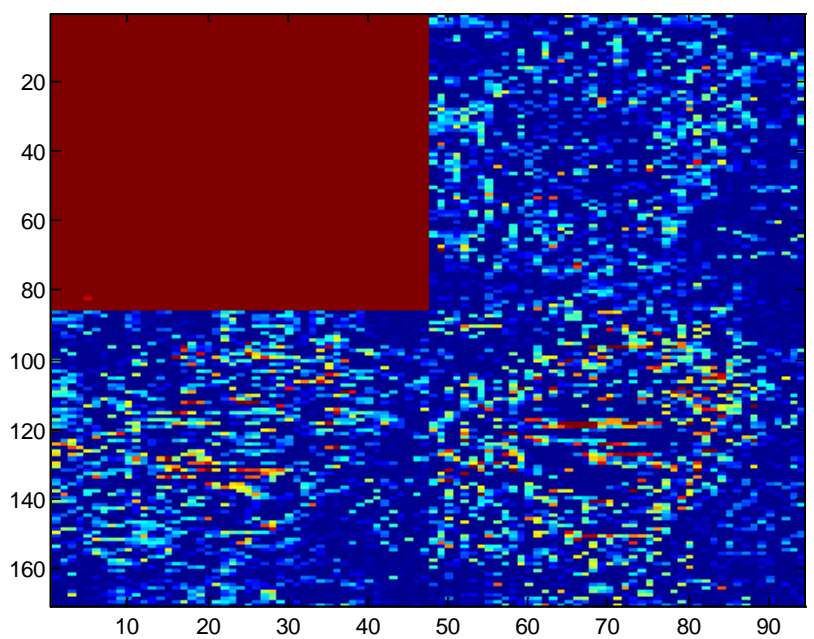

Figure 33. S2-N1-M6 $(80 \times 156)$. 


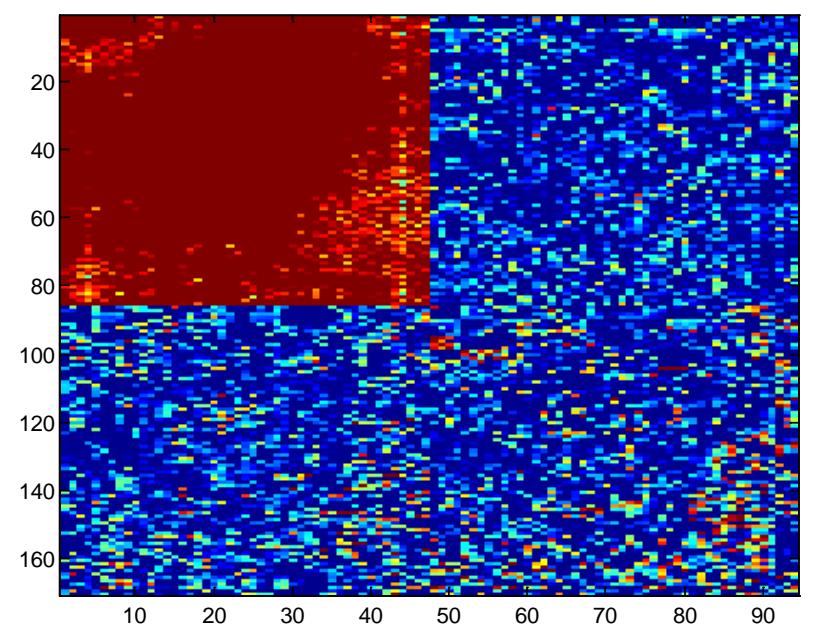

Figure 34. S2-N1-M7 (80 × 156).

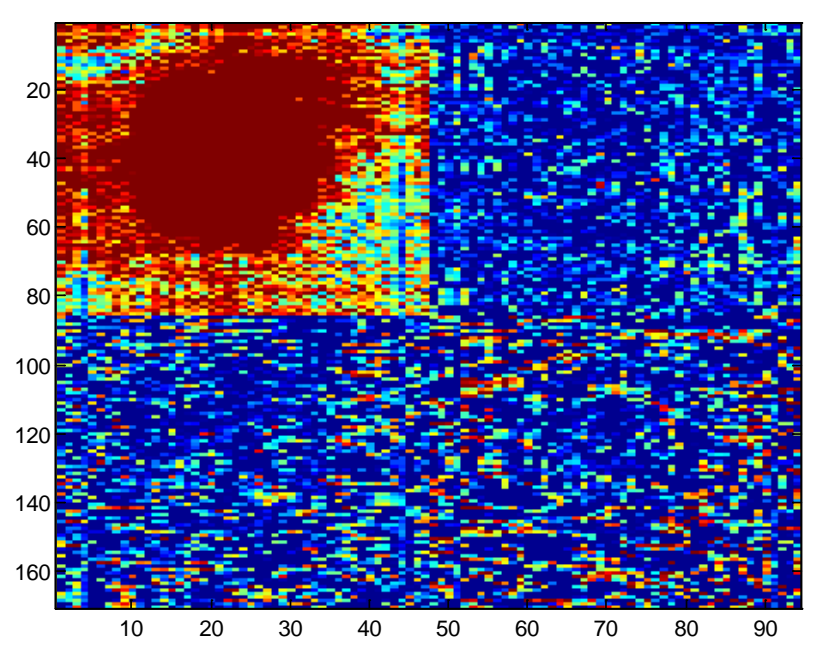

Figure 35. S2-N1-M8 (80 × 156).

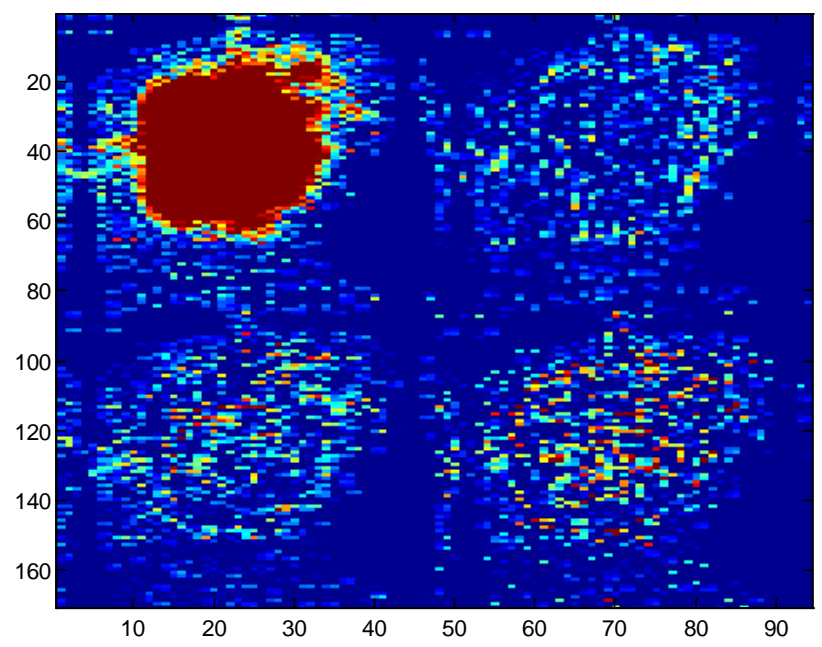

Figure 36. S2-N1-M9 (80 × 156). 


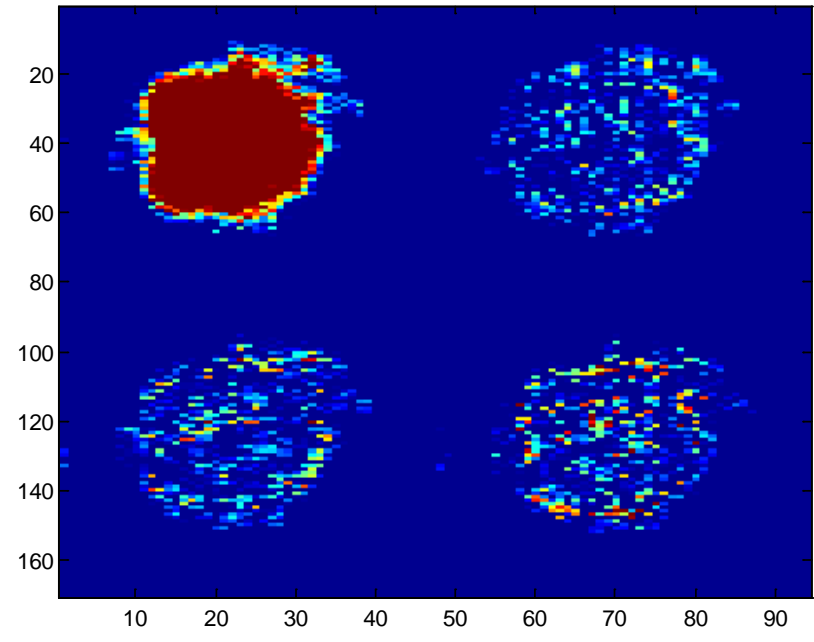

Figure 37. S2-N1-M10 $(80 \times 156)$.

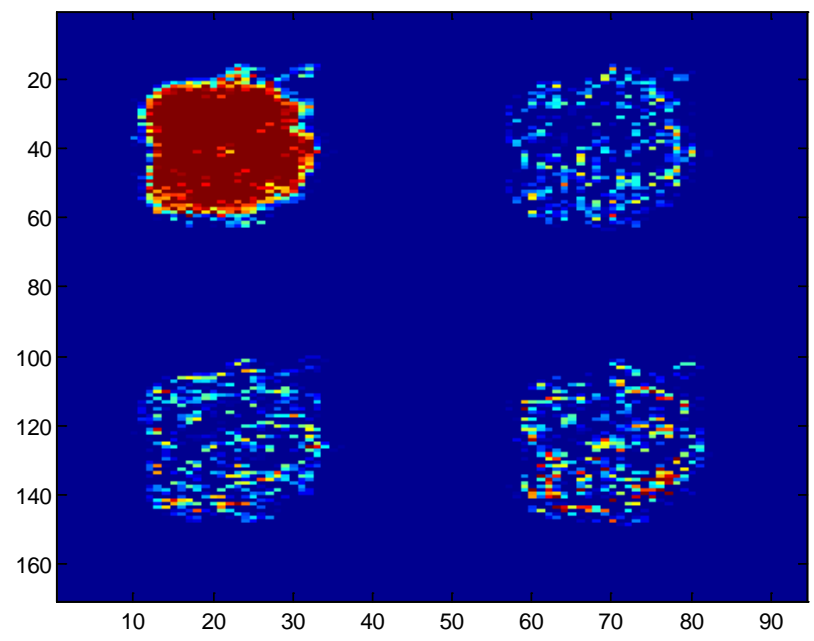

Figure 38. S2-N1-M11 $(80 \times 156)$.

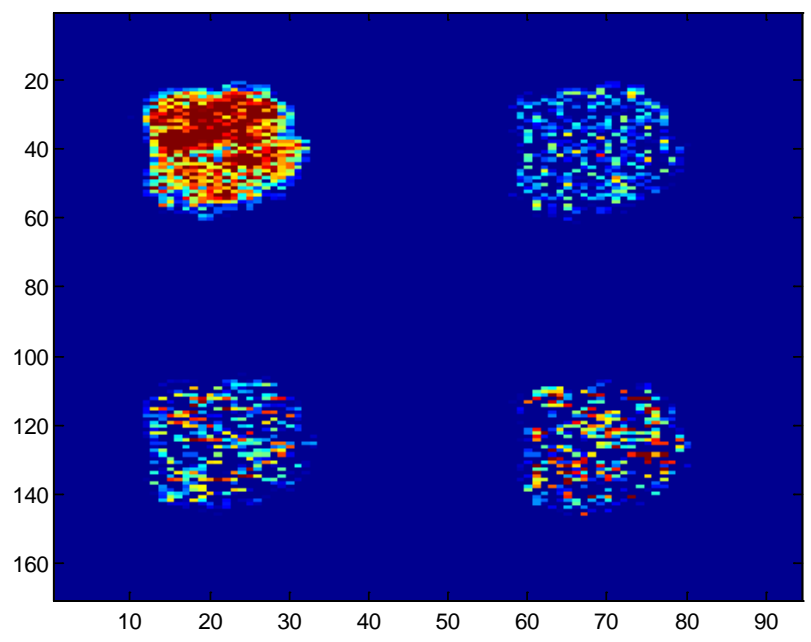

Figure 39. S2-N1-M12 (80 × 156). 


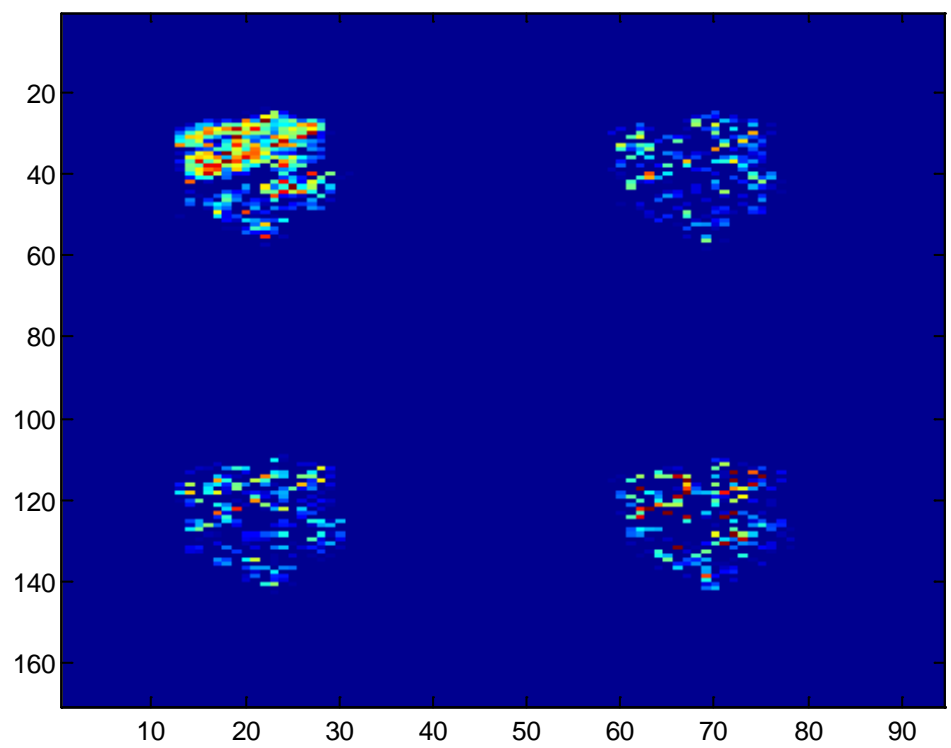

Figure 40. S2-N1-M13 $(80 \times 156)$.

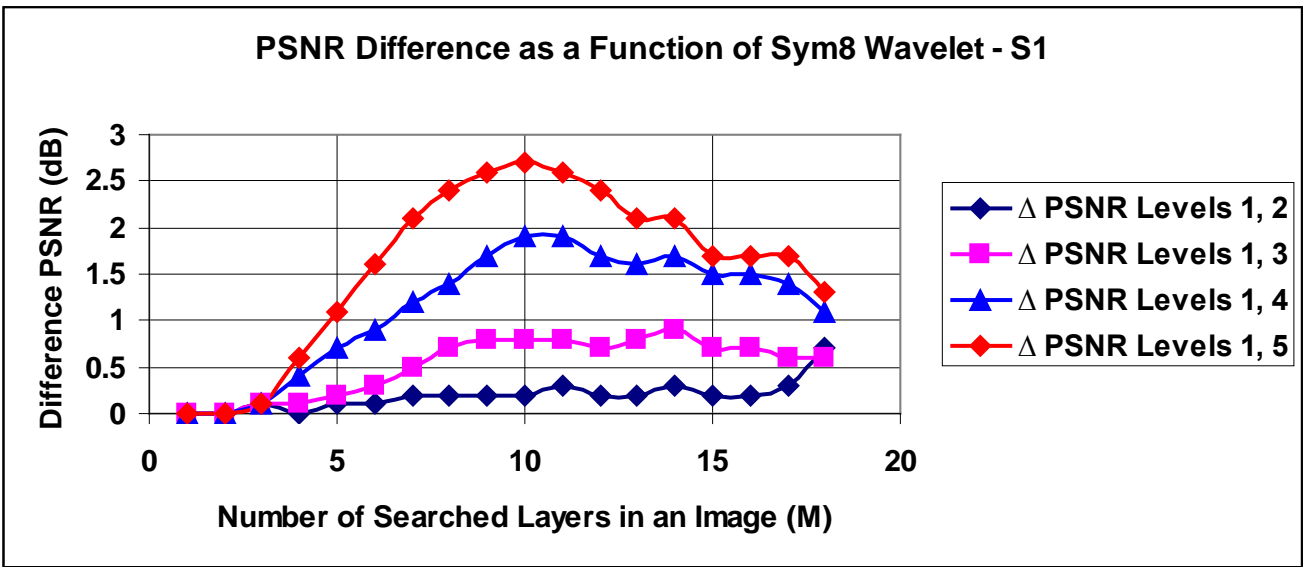

Figure 41. Damage detection in S1 using Sym8.

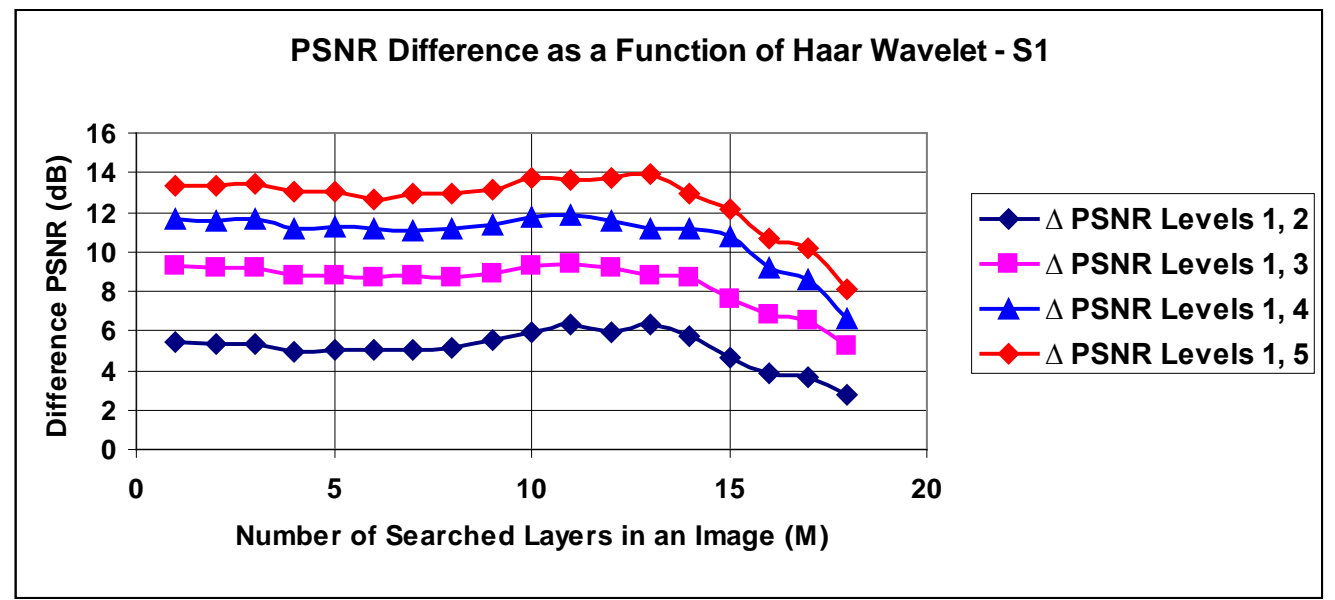

Figure 42. Damage detection in S1 using Haar. 


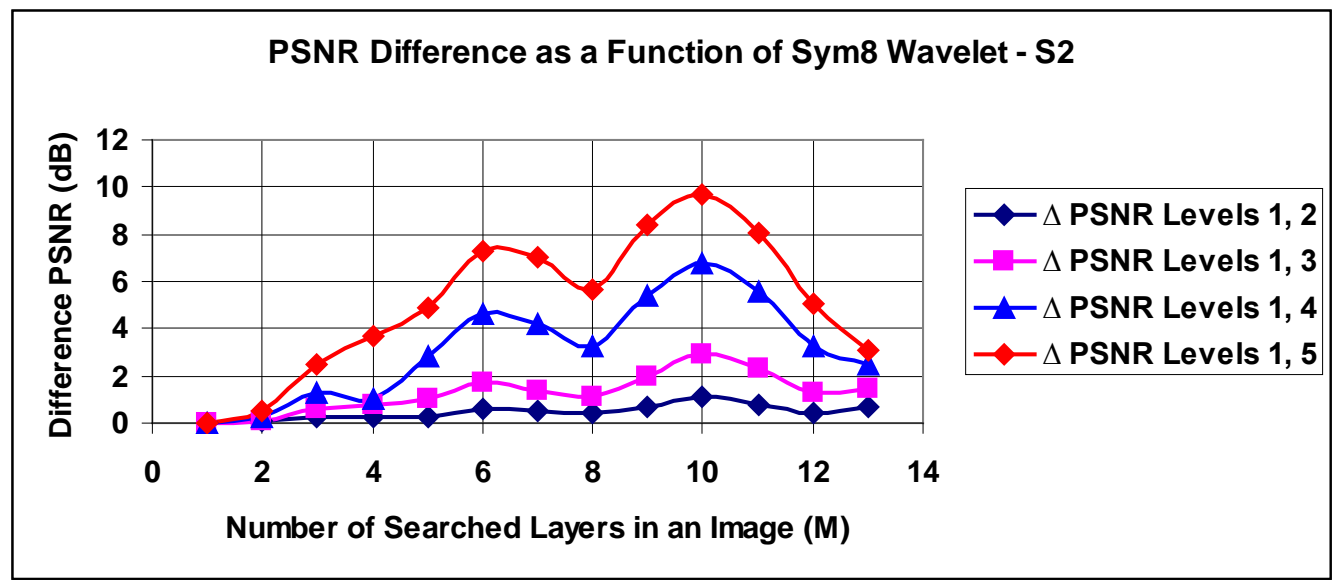

Figure 43. Damage detection in S2 using Sym8.

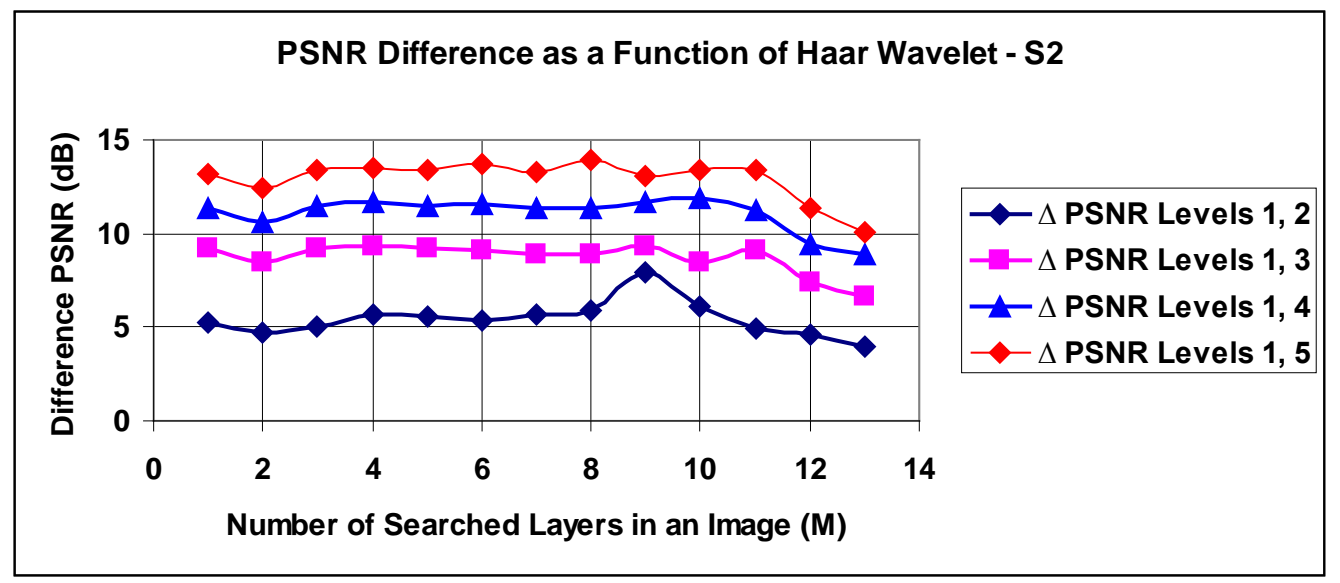

Figure 44. Damage detection in S2 using Haar.

Equations (1) to (4) show the actual difference in behavior of an image search through algorithm, which will be used as input to the algorithm used here employing Difference PSNR and WT. The searched through images for S1 and S2 are shown previously in Figures 10-40. The overall algorithm will make use of Equations (1) to (4) and can be described using Equation (5) as below:

$$
\begin{aligned}
& \lim \triangle P S N R\left(\text { image }_{i}\left(\left|N_{k}-N_{k+1}\right|\right)\right) \rightarrow \lambda \\
& i: 1 \rightarrow M \\
& k: 1 \rightarrow L
\end{aligned}
$$

where

$M$ :Maximum Number of Searched Layers

$L$ :Maximum Number of Wavelet Decomposition Levels

$\lambda$ : Value $(\mathrm{dB})$ Indicating the Presence of Damage

The value of $\lambda$ will correspond to layer numbers described in Equations (1) to (4) as defined in Equation 6:

$$
\lambda_{\text {damage }}=\lambda(Q)
$$

From Figures 41-43, and applying Equations (1) to (6), the following is obtained and summarized in Table 2.

In the specific case of S1, there are two different areas of Impact damage at two different angles to the normal to the surface of the composite sample surface. Hence, Equation (7) and Equations (8) and (9) represent the layer 
Table 2. Impact damage characteristics for vertical load drop.

\begin{tabular}{|c|c|c|c|c|c|c|}
\hline Composite Sample & & $\lambda_{\text {damc }}$ & $e^{-\mathrm{dB}}$ & & Image Layers & Damage Type \\
\hline S1 & $\begin{array}{l}0.2 \\
03\end{array}$ & $\begin{array}{l}0.8 \\
0.8\end{array}$ & $\begin{array}{l}1.9 \\
19\end{array}$ & $\begin{array}{l}2.7 \\
26\end{array}$ & 10,11 & Impact at $\pi / 2$ \\
\hline S2 & $\begin{array}{l}0.6 \\
0.5\end{array}$ & $\begin{array}{l}1.7 \\
1.4\end{array}$ & $\begin{array}{l}4.6 \\
4.2\end{array}$ & $\begin{array}{l}7.3 \\
7.0\end{array}$ & 6,7 & Fiber Breakage and Extraction \\
\hline
\end{tabular}

delay in uncovering the second lighter damage on the surface of the same sample S1:

$$
\begin{gathered}
\lambda_{\text {damage }}(\text { delay })=\lambda\left(Q_{\text {delay }}\right) \\
Q_{T}(\text { delay })=\left(\left[0.5\left(M+\left(\frac{\sin \left(\frac{\pi}{2}\right)}{\sin \left(\theta_{\text {incident }}\right)}\right) \times 2\right)\right]+1\right) \\
Q_{M}(\text { delay })=\left(\left[0.5\left(M+\left(\frac{\sin \left(\frac{\pi}{2}\right)}{\sin \left(\theta_{\text {incident }}\right)}\right) \times 2\right)\right]+2\right)
\end{gathered}
$$

In the case of Sample S1, and substituting the values for impact load incident angles, gives:

From Table 2 and Table 3, damage characteristic matrices $(\mathrm{Ch})$ can be produced as follows:

$$
\begin{aligned}
C h_{1}(S 1) & =\left[\begin{array}{llll}
0.2 & 0.8 & 1.9 & 2.7 \\
0.3 & 0.8 & 1.9 & 2.6
\end{array}\right] \\
C h_{2}(S 1) & =\left[\begin{array}{llll}
0.2 & 0.7 & 1.7 & 2.4 \\
0.3 & 0.8 & 1.6 & 2.2
\end{array}\right] \\
C h(S 2) & =\left[\begin{array}{llll}
0.6 & 1.7 & 4.6 & 7.3 \\
0.5 & 1.4 & 4.2 & 7.0
\end{array}\right]
\end{aligned}
$$

It is realized that:

1) The matrix values for S2 are more than twice the values obtained for S1. This further supports the observation of fiber breakage and fiber extraction and proves the validity of using higher levels of decomposition for selected Sym8 wavelet to detail such values.

2) Taking a sample from the previous image figures (Figure 21 and Figure 36), it is clear that S2 suffered more than twice the impact force, which resulted in fiber breakage and Damage 1 (D1) is S1 has suffered Almost twice the Value of impact compared to Damage (D2) which made contact with the composite sample at an angel $\pi / 6$, with its $\operatorname{Sin}=0.5$. These observations are supported by the diameter of damaged area, as shown in Figure 45 and Figure 46.

3) The difference in the internal coloring of the damaged areas in S1 and S2 samples indicates the severity of damage in S2 compared to S1.

Using such algorithm that employs difference PSNR results in a reduction to the number of layers needed to be inspected closely and stored as an evidence of damaged structure. Also, it accurately points out the area or areas of damage. Also it correlate the severity of damage to both the number of inspected layers and the PSNR values expected for such level of damage [13] [14].

\section{Conclusions}

It is evident from the presented work that:

1) The type of wavelet and level of decomposition have a marked effect on uncovering damage in composite structures when applied to obtained images, which also applies to medical image analysis. 
Table 3. Impact damage characteristics for angled load drop.

\begin{tabular}{ccccccc}
\hline Composite Sample & \multicolumn{4}{c}{$\lambda_{\text {damage }}$ (delay)-dB } & Image Layers & Damage Type \\
\hline & 0.2 & 0.7 & 1.7 & 2.4 & 12,13 & Impact at $\pi / 6$ to the normal of \\
the sample surface
\end{tabular}

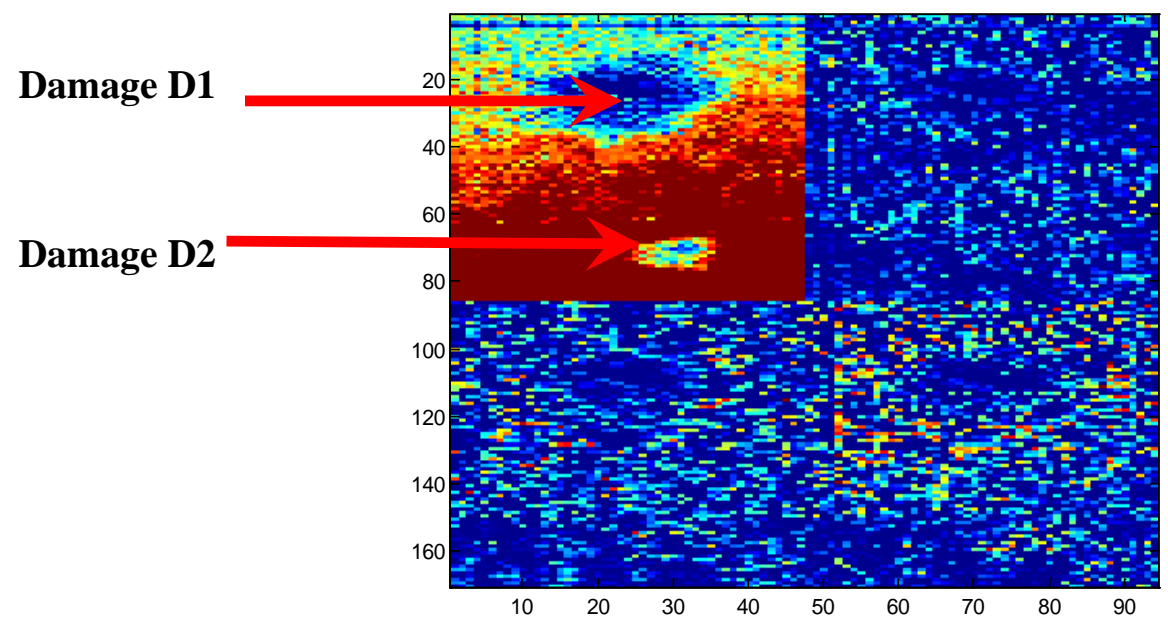

Figure 45. Damaged areas diameter difference in S1.

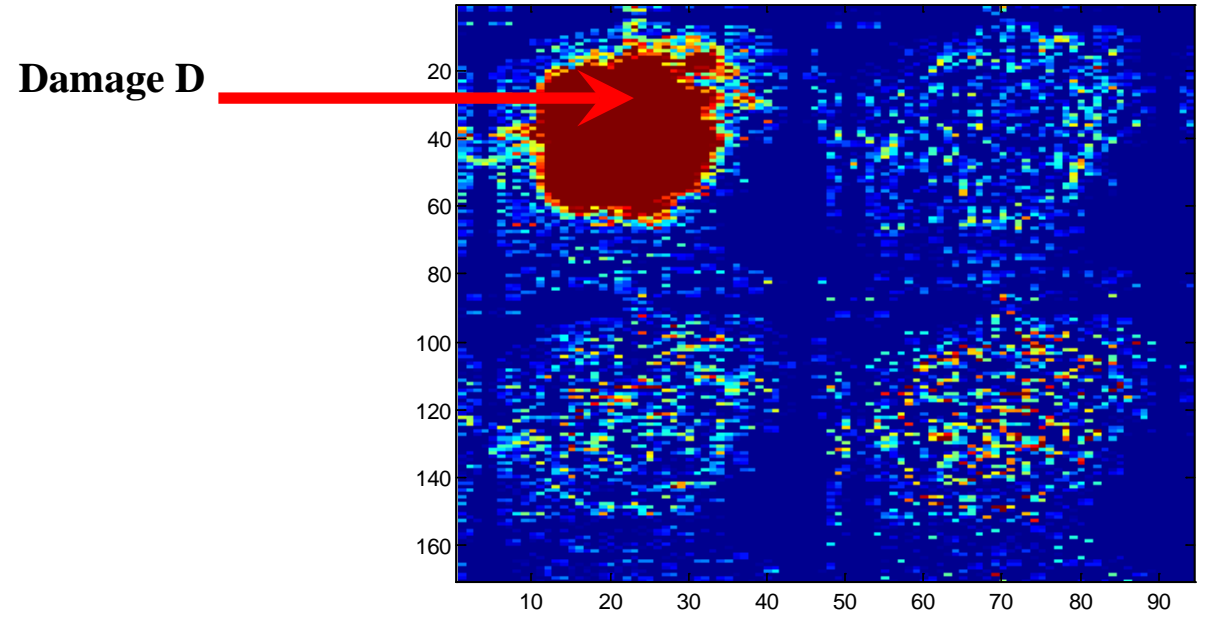

Figure 46. Damaged areas diameter in S2.

2) $\triangle$ PSNR is an excellent approach to zooming on the magnitude of damage in a structure through application of PSNR to images.

3) $\Delta \mathrm{W}$ is a good approach when combined with PSNR to reveal the scale of damage and also provides better details.

4) A definitive relationship is established between PSNR, number of searched layers in an image and level and angle of impact.

The overall work describes a new way to approach damage analysis of images for both medical and composite structures.

This work provided a new approach and technique to NDT. Such approach evaluates structures more accurately as it links the main principles of PSNR and WT into a single algorithm that is applied to uncover level and extent of damage. Such way of testing can be also used to evaluate material strength and ability to withstand impacts. 


\section{References}

[1] Rigdon, S. and Steward, R.M. (2015) The Efficiency of a Wavelet Transformation Approach to Prospective Monitoring. Computer-Aided Civil and Infrastructure Engineering, 30, 151-162.

[2] Yang, Z., Chen, X., Xie. Y., Miao. H., Jao, J. and Qi, K. (2015) Hybrid Two-Step Method of Damage Detection for Plate-Like Structures. Structural Control and Health Monitoring, 23, 267-285.

http://dx.doi.org/10.1002/stc.1769

[3] Dai, H., Zhang, H. and Wang, W. (2015) A Multiwavelet Neural Network-Based Response Surface Method for Structural Reliability Analysis. Quality and Reliability Engineering International, 31, 489-500. http://dx.doi.org/10.1111/mice.12086

[4] Görgel, P., Sertbas, A. and Osman, U. (2015) Computer-Aided Classification of Breast Masses in Mammogram Images Based on Spherical Wavelet Transform and Support Vector Machines. Expert Systems, 32, 155-164. http://dx.doi.org/10.1111/exsy.12073

[5] Peng, F., Li, J. and Long, M. (2015) Identification of Natural Images and Computer-Generated Graphics Based on Statistical and Textural Features. Journal of Forensic Sciences, 60, 435-443. http://dx.doi.org/10.1111/1556-4029.12680

[6] Decowski, J. and Li, L. (2015) Wavelet-Based Tests for Comparing Two Time Series with Unequal Lengths. Quality Journal of Time Series Analysis, 36, 189-208. http://dx.doi.org/10.1111/jtsa.12101

[7] Hao, W., Li, J., Dong, Z., Li, Q., and Yu, K. (2015) An Empirical Study on Compressed Sensing MRI Using Fast Composite Splitting Algorithm and Combined Sparsifying Transforms. International Journal of Imaging Systems and Technology, 25, 302-309. http://dx.doi.org/10.1002/ima.22146

[8] Rajendran, P. and Srinivasan, S.M. (2016) Identification of Added Mass in the Composite Plate Structure Based on Wavelet Packet Transform. Strain, 52, 14-25. http://dx.doi.org/10.1111/str.12154

[9] Liu, L., Jia, Z., Yang, J. and Kasabov, N. (2015) A Medical Image Enhancement Method Using Adaptive Thresholding in NSCT Domain Combined Unsharp Masking. International Journal of Imaging Systems and Technology, 25, 199-205. http://dx.doi.org/10.1002/ima.22137

[10] Zhao, F. and Wang, A. (2015) A Background Subtraction Approach Based on Complex Wavelet Transforms in EDXRF. X-Ray Spectrometry, 44, 41-47. http://dx.doi.org/10.1002/xrs.2576

[11] Smith, R., Jann, K., Ances, B. and Wang, D. (2015) Wavelet-Based Regularity Analysis Reveals Recurrent Spatiotemporal Behavior in Resting-State fMRI. Human Brain Mapping, 36, 3603-3620. http://dx.doi.org/10.1002/hbm.22865

[12] Li, Y., Wang, H., Tkach, J., Roach, D., Woods, J. and Dumoulin, C. (2015) Wavelet-Space Correlation Imaging for High-Speed MRI without Motion Monitoring or Data Segmentation. Magnetic Resonance in Medicine, 74, 1574-1586. http://dx.doi.org/10.1002/mrm.25546

[13] Kumar, B.V. and Harikumar, R. (2015) Performance Analysis of Neural Networks for Classification of Medical Images with Wavelets as a Feature Extractor. International Journal of Imaging Systems and Technology, 25, 33-40. http://dx.doi.org/10.1002/ima.22118

[14] Prats-Montablan, J.M., Cocchi, M. and Ferrer, A. (2015) N-Way Modeling for Wavelet Filter Determination in Multivariate Image Analysis. Journal of Chemometrics, 29, 379-388. http://dx.doi.org/10.1002/cem.2717 